\title{
The Steady-State Creep Behavior of Dental Amalgam*
}

\author{
George Dickson, Philip Oglesby, and Ruth Davenport \\ Institute for Materials Research, National Bureau of Standards, Washington, D.C. 20234
}

(April 30, 1968)

The steady-state creep behavior of a dental amalgam subjected to tensile stresses of 500 to 4000 psi $\left(3.4 \times 10^{6}\right.$ to $\left.2.8 \times 10^{7} \mathrm{~N} / \mathrm{m}^{2}\right)$ was investigated over the temperature range of 23 to $52{ }^{\circ} \mathrm{C}$ ( $(296$ to $325 \mathrm{~K})$. It was found that the creep behavior can be represented by the equation:

$$
\dot{\epsilon}_{v}=K \sigma^{m} e^{-E / R T}
$$

\begin{abstract}
where $\dot{\epsilon}_{r}$ is the creep rate, $K$ and $m$ are constants of the material, $\sigma$ is the stress, $E$ is the activation energy for the process, $R$ is the gas constant and $T$ is the temperature. Values of the constants determined for the dental amalgam were $K=2.31 \times 10^{9}, m=3.45$ and $E=35,300 \mathrm{cal} / \mathrm{mol}(148,000$ joule $/$ mole).
\end{abstract}

Key Words: Amalgam; creep; creep activation energy; dental amalgam; silver amalgam.

\section{Introduction}

In a previous study of the viscoelastic behavior of dental amalgam [1] ${ }^{1}$ it was shown that the viscous strain rate of amalgam at a constant temperature is a nonlinear function of stress which can be represented by an equation of the form:

$$
\dot{\epsilon}_{r}=K \sigma^{m}
$$

where $\sigma$ is the stress and $K$ and $m$ are constants of the material.

The objectives of the present study were (1) to determine the steady-state creep behavior of dental amalgam over a range of temperatures occuring in the mouth, (2) to determine which of the steady-state creep equations from established theory represents the behavior of dental amalgam, and (3) to determine the activation energy of creep of amalgam in order to gain an insight into the dominant mechanism governing the steady-state creep of amalgam.

\section{Theory}

The steady-state creep of a metal may be controlled by such processes as (1) true frictional forces, (2)

*This investigation is part of the dental research program conducted by the National Bureau of Standards, in cooperation with the Council on Dental Research of the American Dental Association; the Army Dental Corps; the Dental Sciences Division of the School of Aerospace Medicine, USAF; the National Institute of Dental Research, National Institutes of Health; and the Veterans Administration.

${ }^{1}$ Figures in brackets indicate the literature references at the end of this paper. thermally activated processes, and (3) quantum mechanical tunneling effects [2]. The quantum mechanical tunneling effects appear to occur only at very low temperatures, if at all. True frictional forces give rise to viscous or quasi-viscous behavior and in examples where quasi-viscous frictional forces appear to determine the creep rate, the energy is usually dissipated by a mechanism which is thermally activated. Thus, most steady-creep processes in metals are thermally activated processes; that is the creep rate depends on the temperature in the relation, exp $(-E / k T)$ where $T$ is the temperature and $E$ is the activation energy of the specific process. The steadystate creep rate may be related to the thermally activated rate processes by the following general equation:

$$
\dot{\epsilon}_{r}=\sum_{i} f_{i}(\sigma, T, \beta) e^{-E_{i}(\sigma, T, \beta) / k T}
$$

where

$\dot{\epsilon}_{r}=$ steady-state creep rate,

$\sigma=$ applied stress

$T=$ temperature (kelvin),

$\beta=$ a crystalline geometric factor,

$E_{i}=$ activation energy for the process, and

$k=$ Boltzmann constant $\left(1.38 \times 10^{-23}\right.$ joule/kelvin $)$.

The activation processes in a metal are controlled by such micromechanisms as (1) climb-softening 
(climbing of dislocations) which is subgrain formation, (2) glide-softening (glide movement of dislocations) which is crystallographic slip, (3) flow of grain boundaries, (4) diffusion of vacancies (Nabarro-Herring mechanism) and (5) twinning [2].

Twinning occurs only at low temperatures and high stresses under tensile test conditions and therefore, is not ordinarily an important factor in steady-state creep [2].

The Nabarro-Herring mechanism contributes to steady-state creep only at temperatures near the melting point and at extremely low stresses [2].

The amount that flow of grain boundaries contributes to the steady-state creep is unclear, but it does contribute in some cases [2].

Glide-softening has as its main cause cross slip [3]. It can occur at low temperatures (below one half the melting temperature, $T_{m}$ ). Since glide-softening occurs while the dislocations are gliding, it occurs only at sufficiently high stresses and at short times in creep behavior and therefore, is not important in slow creep such as steady-state creep.

In the cases of climb-softening, the cause is vacancy creep [3]. Vacancy creep is a function only of temperature, not of stress. The mobility and concentration of vacancies must be great enough for vacancy creep to occur; this critical mobility and concentration of vacancies occurs for most metallic elements at approximately $1 / 2$ the melting temperature of the element. Thus, climb-softening occurs for most metals only above $0.5 T_{m}$ and unlike glide-softening can occur at low stresses and allows large strains to develop over long periods of time. Therefore, climbsoftening is one of the principle mechanisms of steady-state creep and is pronounced at temperatures above about $0.5 T_{m}$. The climb-softening allows edge dislocations (1) to move out of their glide surfaces, (2) to annihilate or polygonize with other dislocations and (3) to pass around obstacles. The climb of the dislocations from their glide surfaces is achieved by absorbing or emitting vacancies. The forces necessary to achieve climb are obtained from local stress fields and the interaction with other dislocations; these forces are often small enough for creep due to climbsoftening to be Newtonian [3] and described by the following equation:

$$
\dot{\epsilon}_{v}=K \sigma e^{-E / R T}
$$

where

$$
\begin{aligned}
& \dot{\epsilon}_{v}=\text { steady-state creep rate } \\
& \sigma=\text { stress, } \\
& E=\text { activation energy of self-diffusion, } \\
& R=\text { gas constant, and } \\
& T=\text { temperature (kelvin). }
\end{aligned}
$$

However, even though the steady-state creep may be controlled by Newtonian vacancy creep (climbsoftening) the resulting creep may be non-Newtonian due to the fact that the number of climbing dislocations, their driving stresses and their climbing distances depend on the dislocation density which is dependent on the applied stress [3]. The rate of steady-state creep in the case of many metals may be represented by either of the following equations which are nonNewtonian in the stress relation but thermally activated:

$$
\dot{\epsilon}_{v}=K \sigma^{m} e^{-E / R T} \text { (Dorn equation) }
$$

or

$$
\dot{\epsilon}_{v}=A e^{\beta \sigma} e^{-E / R T}(\text { Kauzmann equation })
$$

\section{Experimental Procedure}

The material and experimental procedures were as described by Oglesby, et al. [1]. Amalgam specimens were made by mixing mercury with a commercial alloy for dental amalgam (composition approximately Ag $70 \%$, Sn $26 \%, \mathrm{Cu} 3.5 \%, \mathrm{Zn} 0.5 \%$ ) and condensing the mixture into a metal mold. The dumbbell shaped specimens formed in the mold were 0.75 in $(19 \mathrm{~mm})$ long, with a straight portion 0.3 in $(8 \mathrm{~mm})$ in length having a square cross section $0.1 \times 0.1$ in $(2.5 \times 2.5$ $\mathrm{mm})$.

Tensile stresses ranging from approximately 500 to 4000 psi $\left(3.4 \times 10^{6}\right.$ to $\left.2.8 \times 10^{7} \mathrm{~N} / \mathrm{m}^{2}\right)$ were applied to the specimens. Strain was measured to approximately $1 \times 10^{-4}$ in per in with Tuckerman optical strain gages attached to the straight portion of the specimen. Creep rates were determined from the slope of the straight line portion of the loaded creep curve.

The steady-state creep rates were determined over the temperature range of 23 to $52{ }^{\circ} \mathrm{C}$ (296 to $325 \mathrm{~K}$ ) and over the stress range of 500 to $4000 \mathrm{psi}\left(3.4 \times 10^{6}\right.$ to $\left.2.8 \times 10^{7} \mathrm{~N} / \mathrm{m}^{2}\right)$.

\section{Results and Discussion}

The steady-state creep rate was found to be nonlinear as a function of the stress for any fixed temperature, figure 1. It was further found that $\log _{e}$ of the creep rate was nonlinear as a function of stress at constant temperature. However, when the $\log _{e}$ of the creep rate was plotted as a function of the $\log _{e}$ of the stress a straight line was obtained at any given temperature, figure 2. These $\log _{e} \dot{\epsilon}_{v}$ versus $\log _{e} \sigma$ plots were made for fixed temperatures over the range 23 to $52{ }^{\circ} \mathrm{C}(296$ to $325 \mathrm{~K})$ and the slope of the straight line obtained at each temperature was determined and found to be approximately 3.5 for all the linear plots as shown in figure 2. This indicated that the steady-state creep rate could be approximated as a function of stress by the following relation:

$$
\dot{\epsilon}_{v}=K \sigma^{m} f(T)
$$

where $m$ is the slope of the linear plot of $\log _{e} \dot{\epsilon}_{i}$ versus $\log _{e} \sigma$. 


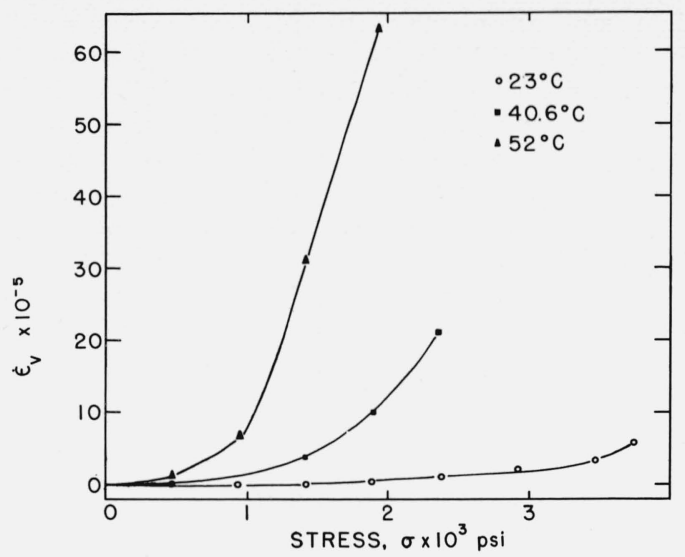

FIGURE 1. Steady-state creep rate, $\epsilon_{v}$, of dental amalgam versus stress.

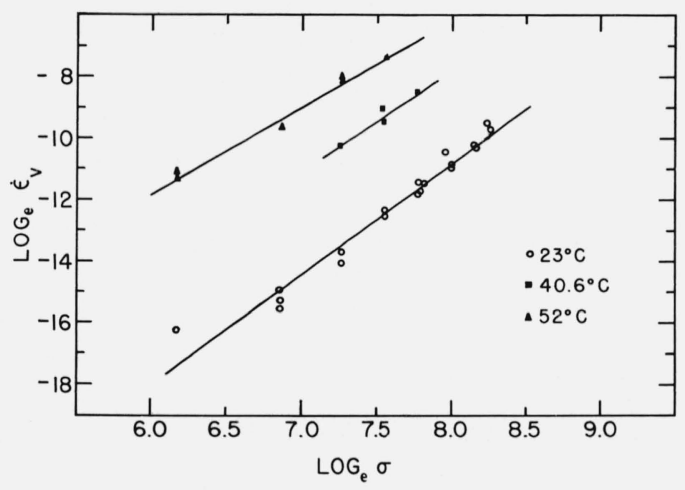

FigURE 2. $\log _{e}$ of steady-state creep rate, $\boldsymbol{\epsilon}_{v}$, of amalgam versus $\log _{e}$ of stress, $\sigma$.

Next the steady-state creep rate was examined as a function of temperature at various fixed stresses. The plots of creep rate versus $T$ and $1 / T$ were found to be nonlinear. However, a plot of the $\log _{e}$ of the creep rate versus $1 / T$ was found to be linear at fixed stress values of approximately 1400 and 1900 psi $\left(9.6 \times 10^{6}\right.$ and $\left.1.3 \times 10^{7} \mathrm{~N} / \mathrm{m}^{2}\right)$, figure 3 ; and straight lines were drawn through the two points for each of the other fixed stress values. The slope of these linear plots of $\log _{e} \dot{\epsilon}_{v}$ versus $1 / T$ were approximately the same for the different fixed values of stress as shown in figure 3 . Thus, the steady-creep rate $\dot{\epsilon}_{v}$ could be related to the absolute temperature by the following relationship:

$$
\dot{\epsilon}_{v}=K e^{-C / T} f(\sigma)
$$

where $C=$ the negative of the slope of the $\log _{e} \dot{\epsilon}_{v}$ versus $1 / T$ where $T$ is in kelvin. Now from theory [2] $C$ is related to the activation energy of steady-state creep for a single micromechanism by the following relation:

$$
E / R=C
$$

where $R$ is the ideal gas constant $\left(1.99\right.$ calories per ${ }^{\circ} \mathrm{C}$ per mole; 8.31 joules per kelvin per mole). However,

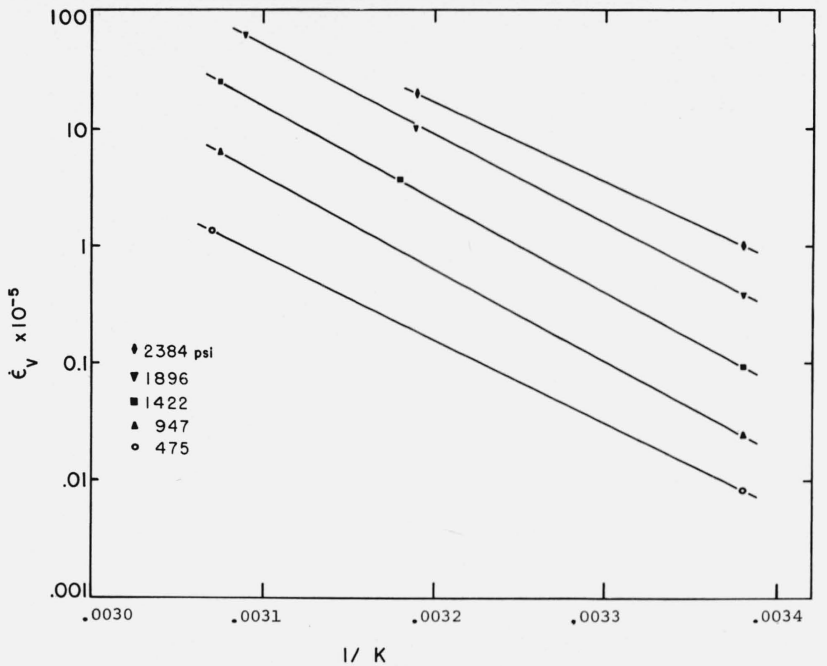

FIgURE 3. Steady-state creep rate, $\boldsymbol{\epsilon}_{v}$, of amalgam plotted on a logarithmic scale versus the reciprocal of absolute temperature, $K$.

when there are a number of micromechanisms involved the value of $E$ is an average or combination activation energy usually representative of the dominant mechanism governing the steady-state creep process [2]. This activation energy $E$ was calculated from the slopes in figure 3 and found to be about $35,000 \mathrm{cal} / \mathrm{mole}(150,000$ joule/mole).

Combining the results obtained from the plots of $\log _{e}$ of creep rate versus $\log _{e} \sigma$ at a constant temperature and the plots of $\log _{e}$ of creep rate versus $\frac{1}{T}$ at a constant stress gives the following equation for the steady-state creep of dental amalgam within the stress temperature ranges studied:

$$
\dot{\epsilon}_{v}=K \sigma^{m} e^{-E / R T} .
$$

A least squares fit of the equation

$$
\log _{e} \dot{\boldsymbol{\epsilon}}_{v}=\log _{e} K+m \log _{e} \sigma-\frac{E}{R T}
$$

to all of the data gave the following values and standard deviations for the constants:

$$
\begin{aligned}
m= & 3.45 \pm 0.11 \\
E= & 35,300 \mathrm{cal} / \mathrm{mol} \pm 1,100 \mathrm{cal} / \mathrm{mol}(148,000 \text { joule } / \\
& \text { mole } \pm 4,600 \mathrm{joule} / \mathrm{mole})
\end{aligned}
$$$$
\log _{e} K=21.6 \pm 1.5 \text {. }
$$

In figure 4 a plot of $\log _{e} \dot{\epsilon}_{v}+\frac{E}{R T}$ versus $\log _{e} \sigma$ shows a comparison of the experimental data with the curve calculated using these constants.

Since the steady-state creep rate of dental amalgam could be related to the temperature by the function $\exp (-C / T)$, it is concluded that the dominant process controlling the creep rate of amalgam is a thermally activated one. 


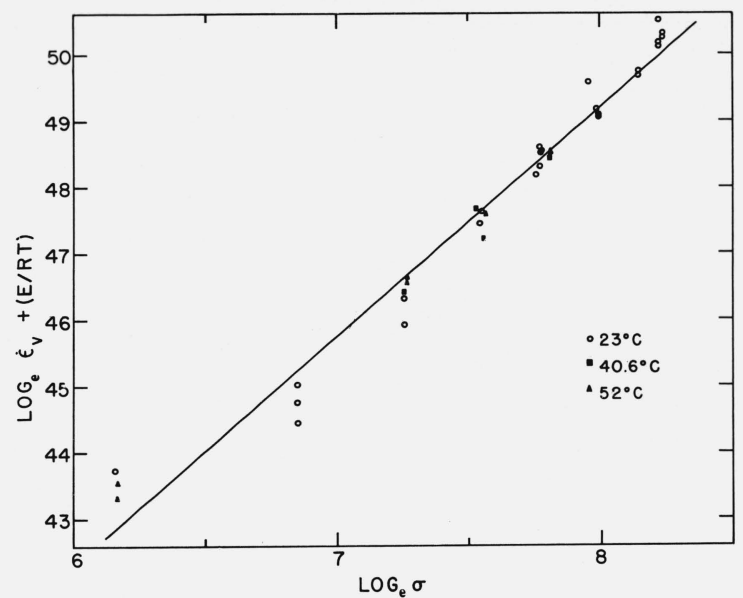

Figure 4. Comparison of experimental points with curve calculated from the constants determined for the equation

$$
\dot{\epsilon}_{\mathrm{v}}=\mathrm{K} \sigma^{\mathrm{m}} \mathrm{e}^{-\mathrm{E} / \mathrm{RT}}
$$

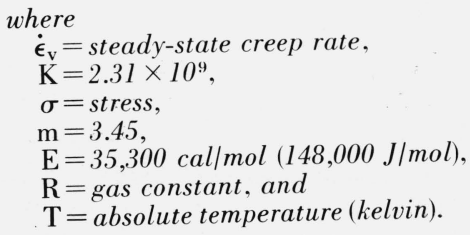

The results suggest that the dominant micromechanism involved in the creep of dental amalgam in the temperature range studied is diffusion controlled climbing of dislocations (subgrain formation). This is supported by the evidence that the controlling process is thermally activated and by the fact that the temperature involved is above $0.5 T_{m}$. (The solidus temperature of amalgam as indicated by the appearance of liquid mercury is near $355 \mathrm{~K}$.)

Activation energy for high temperature creep in pure metals corresponds generally to the activation energy of self diffusion [2, 3]. Little quantitative information is available on diffusion in dental amalgam. It is of interest to note, however, that the activation energy found for creep of amalgam lies within the range of energies of self diffusion reported for the metals, other than mercury, contained in dental amalgam, table 1 .

TABLE 1. Activation energy

\begin{tabular}{|c|c|c|c|c|c|}
\hline & \multicolumn{2}{|c|}{ Creep } & \multicolumn{2}{|c|}{ Self-diffusion } & \multirow[t]{2}{*}{ Reference } \\
\hline & $\mathrm{kcal} / \mathrm{mol}$ & $\mathrm{kJ} / \mathrm{mol}$ & $\mathrm{kcal} / \mathrm{mol}$ & $\mathrm{kJ} / \mathrm{mol}$ & \\
\hline Amalgam....... & 35 & 146 & & & \\
\hline Silver........................ & & & $\begin{array}{r}44-46 \\
6-10\end{array}$ & 184-193 & [7] \\
\hline $\begin{array}{l}\text { Tin } \ldots \ldots \ldots \ldots \ldots \ldots \ldots \ldots \\
\text { Copper } \ldots \ldots \ldots \ldots \ldots \ldots\end{array}$ & $\begin{array}{l}21-26 \\
44\end{array}$ & $\begin{array}{c}88-109 \\
184\end{array}$ & $\begin{array}{l}6-10 \\
48^{6}\end{array}$ & $\begin{array}{l}2 b^{-42} \\
201\end{array}$ & $\begin{array}{l}{[7]} \\
{[2]}\end{array}$ \\
\hline Zinc.................................. & 27 & 113 & 20 & 84 & {$[2]$} \\
\hline Mercury $\ldots \ldots \ldots \ldots \ldots \ldots$ & 1.2 & 5.0 & $1.0-1.2$ & $4.2-5.0$ & {$[8,9]$} \\
\hline
\end{tabular}

Since the dominant mechanism controlling the thermally activated steady-state creep in amalgam in the range 298 to $328 \mathrm{~K}$ is probably climb of dislocations, the activation energy of which is the activation energy of diffusion, studies of the diffusion of the components into each phase of amalgam should be made to determine the activation energies. Also studies of the steady-state creep behavior of each phase of dental amalgam should be made to determine which phase or phases of dental amalgam dominate its steady-state creep behavior.

\section{Conclusions}

The steady-state creep behavior of dental amalgam in the temperature range 296 to $325 \mathrm{~K}$ and the stress range 500 to $4000 \mathrm{psi}\left(3.4 \times 10^{6}\right.$ to $\left.2.8 \times 10^{7} \mathrm{~N} / \mathrm{m}^{2}\right)$ can be represented by the equation:

$$
\dot{\epsilon}_{v}=K \sigma^{m} e^{-E / R T}
$$

with $m=3.45$ and $E=35,000 \mathrm{cal} / \mathrm{mol}(148,000$ joule/ mole).

The creep behavior is probably controlled by a thermally activated process dominated by the mechanism of climb of dislocations.

\section{References}

[1] Oglesby, P. L., Dickson, G., Davenport, R. M., Rodriquez, M. S., and Sweeney, W. T., Viscoelastic behavior of dental amalgam, J. Res. NBS 72C (Engr. and Inst.), No. 3, 203 (1968).

[2] Schoeck, G., Theories of Creep, Chapter in Mechanical Behavior of Materials at Elevated Temperatures. Dorn, J. Ed. (McGrawHill Book Co., Inc., New York, 1961).

[3] Cottrell, A. H., The Mechanical Properties of Matter (John Wiley \& Sons, Inc., New York, N.Y., 1964).

[4] Dorn, J. E., J. Mech. Phys. Solids 3, 85 (1954).

[5] Weertman, J., Theory of Steady-State Creep Based on Dislocation Climb. J. Appl. Phys. 26, 1213 (1955).

[6] Kauzmann, W., Flow of solid metals from the standpoint of chemical-rate theory, Trans. A.I.M.E. 143, 57 (1941).

[7] Conrad, H., The Role of Grain Boundaries in Creep and Stress Rupture. Chapter in Mechanical Behavior of Materials at Elevated Temperatures, Dorn, J. Ed. (McGraw-Hill Book Co., Inc., New York, N.Y., 1961).

[8] Nachtrieb, M. H., and Petit, J., Self-diffusion in liquid mercury, J. Chem. Phys. 24, 746 (1956).

[9] Hoffman, R. E., The self-diffusion of liquid mercury, J. Chem. Phys. 20, 1567 (1952). 


\section{Publications of the National Bureau of Standards*}

\section{Selected Abstracts}

A review of studies made on the decade fluctuations in the earth's rate of rotation, W. R. Davey, Tech. Note 358 (Oct. 16, 1967) 20 cents.

Studies of variations in the length of the day (l.o.d.) on the order of a few milliseconds over the period of a few decades are briefly reviewed. In this connection, studies of the dynamo theory of geomagnetism, the westward drift of the magnetic field, and electromagnetic core-mantle coupling preface the theory of the decade fluctuations in the l.o.d.

Key Words: Core-mantle coupling; decade fluctuations; dynamo theory; earth's core; geomagnetism; rotation of the earth; westward drift.

Activation analysis: Cockeroft-Walton generator, nuclear reactor, Linac, July 1966 through June 1967, Ed. J. R. DeVoe, Tech. Note 428 (Nov. 1967), 55 cents.

This is the first separate (not combined with that of Radiochemical Analysis) summary of progress for the Activation Analysis Section of the Analytical Chemistry Division of the National Bureau of Standards.

Pertinent information on the irradiation facilities of the nuclear reactor, Linac and Cockcroft-Walton generator are described. The initial installation of pneumatic transfer tubes is completed. Of great significance is the completion of a clean room that is used for pre-irradiation chemical separation for high sensitivity activation analysis.

A dual-sample biaxial rotating $14 \mathrm{MeV}$ neutron-irradiation assembly has been tested. This assembly is part of a system that is controlled by a relay type of programmer to automate those irradiation steps that adversely affect precision of the analysis. This system was used to improve greatly the precision of analysis for oxygen and fluorine.

As a result of improved precision with the $14 \mathrm{MeV}$ neutron irradiation, a study of systematic errors is now possible. Efforts to establish a reproducible correction factor for neutron and gamma-ray absorption between different matrices within the sample have shown considerable promise.

Standard Reference Material (SRM) steel chip Nos., 3b, 3c, and 30f have been analyzed for vanadium. Preliminary analyses of high purity platinum (a potential SRM) showed silver, copper, gold, palladium, and iridium at the ppm level. Future biological SRM's, (tree leaves, and beef liver) were tested for homogeneity and found satisfactory.

A variety of service analyses were performed. In particular, very pure aluminum was found to contain fractions of a ppm of chromium and scandium.

Additional efforts are being made to monitor reactor neutron fluxes. Additional nuclear instrumentation is being assembled to improve the versatility of the analysis technique.

Performance of the bremsstrahlung target, used with the linear electron accelerator, has been evaluated. Photon intensity distribution and stability was found to be within usable range. Analyses using the $(\gamma, n)$ or $(\gamma, p)$ reactions have been developed for mag. nesium in steels, and carbon in sodium metal.

Key Words: NBS reactor; NBS Linac; Cockcroft-Walton generator; digital computers; activation analysis; Standard Reference materi- als; photoneutron reactions; flux monitors: vanadium in irons and steels; homogeneity testing; biological, botanical samples; carbon in sodium; self absorption corrections; high precision $14 \mathrm{MeV}$ neutron activation; instrumentation; flux monitors.

Activities of the NBS Spectrochemical Analysis Section, July 1966 through June 1967, Ed. B. F. Scribner, Tech. Note 422 (Jan. 1968), 45 cents.

A summary is given of activities of the NBS Spectrochemical Analysis Section for the year July 1966 through June 1967. In optical spectrometry, studies were made of (1) the effectiveness of a liquid Q-switch for laser pulse control and (2) the applicability of the high-frequency plasma torch in atomic emission and absorption spectroscopy. Two papers on laser probe spectrochemical analysis were published. In electron probe microanalysis an alignment procedure was developed for the $\mathrm{x}$-ray spectrometer, data on x-ray mass absorption coefficients were collected and critically evaluated, and a review of techniques for scanning microprobe analysis was published. The factors entering into quantitative electron probe analysis are being investigated. In $\mathrm{x}$-ray spectrometry studies were made of interferences especially in the analysis of complex alloys. A combination of techniques involving enrichment by electrodeposition, stable isotope dilution, and determination by the spark source mass spectrometer has provided an accurate method for trace analysis. Improvements in the Section's equipment, including digital readout devices, and developments in computer applications are also discussed. Listings are given of 15 publications and 23 talks by members of the Section during the year.

Key Words: Computing; digital readout; electron probe; gold analysis; isotope dilution method; laser probe; liquid Q-switch; mass attenuation coefficients; microphotometer; optical spectrometry; plasma torch; platinum analysis; preconcentration; selenium analysis; spark source mass spectrometry; spectrochemical analysis; standard reference materials; sulfur analysis; time-shared computer; $\mathrm{x}$-ray absorption coefficients; $\mathrm{x}$-ray fluorescence analysis; vacuum spectrometer.

Analytical coordination chemistry: titrimetry, gravimetry, flame photometry, spectrophotometry, and gas evolution, July 1966 to June 1967, Ed. O. Menis, Tech. Note 424 (Jan. 1968), 55 cents.

In the related areas of gravimetry, titrimetry, flame emission and atomic absorption spectroscopy, absorption and fluorescence spectrophotometry, and gases in metals, the versatile aspects of coordination chemistry have, in several instances, been uniquely exploited to yield either more precise and accurate results or lower detection limits. Fivefold improvement in the gravimetric analysis for beryllium has been obtained by means of an incomplete homogeneous precipitation followed by a selective spectrophotometric examination of the filtrate. In the field of thermal analysis a survey of fifteen compounds has revealed several promising, future stand ards for DTA studies covering the range of 75 to $900{ }^{\circ} \mathrm{C}$. In the section on titrimetry highly precise procedures are described for the determination of boron and beryllium. Various instrumental parameters have been investigated in flame emission and atomic absorption spectroscopy in order to optimize such variables as nebulizerburner and oxidant-fuel systems, elimination of interferences, and source difficulties. The use of chelate extraction systems has led to the extension of detection limits to the submicrogram level for impurities in zinc and selenium, while modified electronics 
has permitted the precise determination of 10 percent $\mathrm{Li}_{2} \mathrm{O}$ in glass with a relative standard deviation of better than 0.2 percent. In absorption and fluorescence spectrophotometry the research aspect of ternary complexes or mixed chelates are described together with their potential use at the nanogram-picogram level. In the same area improvement in accuracy has been obtained by controlled dissolution of samples in closed systems with particular attention being given to the determination of arsenic in cast iron. Also described in this section is the differential spectrophotometric determination of dysprosium in a glass to be used as a neutron flux monitor, in which case the relative error was reduced to less than 0.25 percent. Finally, in the area of high vacuum fusion a new standard was certified for oxygen in titanium and in two titanium alloys. In addition, research in the use of the same technique for the determination of nitrogen has apparently eliminated the problem of low values that have in the past so frequently plagued the analyst.

Key Words: Absorption and fluorescence spectrophotometry; arsenic; atomic absorption; beryllium; DTA studies; dysprosium in a glass; flame emission; gases in metals; gravimetry; home geneous precipitation; impurities in zinc and selenium; $\mathrm{Li}_{2} \mathrm{O}$ in glass; nitrogen; oxygen in titanium; titrimetry.

Calculation of the properties of vacancies and interstitials. Proceedings of a Conference May 1-5, 1966, Ed. A. D. Franklin, Misc. Publ. 287 (Nov. 17, 1967), \$2.50.

This is the Proceedings of a Conference on the Calculation of the Properties of Vacancies and Interstitials, Skyland, Virginia, USA held on May 1-5, 1966. The Conference dealt with the theory and techniques of calculation of the properties of point defects in metallic and nonmetallic crystals. The contributed and invited papers divided about evenly among three major topics: (1) static-lattice calculations of the energies and configurations of simple vacancies and interstitials in, mainly, metals and ionic crystals; (2) electronic states at and near point defects in metals, rare gas solids, and insulators ( $f$-centers, electron traps); and (3) vibrational states at point defects. The report of a panel discussion on each topic is also included. The emphasis is on the theory of the properties of isolated, simple defects rather than on the statistical properties of defect assemblies. The Conference attempted to examine the point defect theory and calculations critically, from the standpoint of general theory, rather than simply compare results with experiment.

Key Words: Calculations; electronic states; energies of formation; energies of motion; interstitials; point defects; theory; vacancies; vibrational states.

\section{Disclosures on: Autosort-an automatic collating and sort- ing machine, optical heterodyne refractometer, liquid metering pump, stable wideband relaxation oscillator using three inverting amplifiers, and seat belt webbing abrasion resistance testing machine, Ed. D. Robbins and A. J. Englert, Tech. Note 437 (Nov. 1967), 25 cents. \\ This booklet presents descriptions and drawings of five devices that embody interesting and unusual solutions to problems frequently encountered in their respective fields. The devices are: \\ Autosort - An Automatic Collating and Sorting Machine \\ Optical Heterodyne Refractometer \\ Liquid Metering Pump \\ Stable Wideband Relaxation Oscillator Using Three Inverting Amplifiers \\ Seat Belt Webbing Abrasion Resistance Testing Machine}

Key Words: Automatic document distribution; programmed document distribution; rotatable document bin array; optical refractive index; laser beam phase shift; laser heterodyning; flexible tubing pump; liquid metering pump; relaxation oscillator; inverting am plifiers; seat belt webbing abrasion; abrasion resistance testing.

Evaluation of information systems: A selected bibliography with informative abstracts, M. M. Henderson, Tech. Note 297 (Dec. 1967), \$1.00.

A survey of the literature on evaluation of information systems has been conducted by the Technical Information Exchange, Center for Computer Sciences and Technology, National Bureau of Standards. During the early stages of the survey, the literature was divided among descriptions of programs which compared the performance of two or more information systems, accounts of programs which studied the performance of one system, papers and reports which discussed the problems of evaluation programs, and documents which proposed new techniques for evaluation of systems. From the total literature collected, those references which were judged to be most directly concerned with the subject of evaluation of information systems were selected and abstracted. The abstracts are designed to give a summary of the content of the corresponding paper; the author's own wording was used extensively, in order to avoid misinterpretation. All of the references collected are listed, in alphabetic order of authors' names, in the appendix to the main body of this publication.

Key Words: Evaluation; performance; testing of information systems; effectiveness; relevance.

Fire resistance of steel deck floor assemblies, $H$. Shoub and S. H. Ingberg, Bldg. Sci. Series 11 (Dec. 1967), 25 cents.

Tests were conducted to determine the resistance to fire of welded steel plate and beam floor assemblies with various conditions of floor covering on the plates, and ceiling protections beneath the beams. The trials included fire exposures from the burnout of combustible materials ranging from 10 to $40 \mathrm{lb} / \mathrm{ft}^{2}$ on the floor surface as well as standard fire endurance tests in which the ceiling of the structure was exposed to fire.

The results of the tests indicated that the use of steel floor structures was practical from considerations of fire safety. For the test conditions established, fire exposure on top of the floor did not heat the structural steel supporting members sufficiently to cause load failure or collapse, and did not produce untenable conditions in the room below. In tests involving fire exposure to the underside of floors, the fire endurance times, based solely on heat transmission criteria, ranged from $1 \mathrm{hr} 24 \mathrm{~min}$ to over $4 \mathrm{hr}$. Temperature levels attained by the structural members and deflection of the floor assemblies are also reported.

Key Words: Fire endurance; steel plate floors; burnout tests; floor tests; fire severity.

Low temperature mechanical properties of copper and selected copper alloys. A compilation from the literature, R. P. Reed and R. P. Mikesell, Mono. 101 (Dec. 1, 1967), \$2.75.

In the past 60 years considerable data has accumulated concerning the mechanical properties of copper and its alloys. It was felt that there was a great need to adequately document these results in one publication. Therefore a unique type of compilation is presented. The compilation is divided into four parts. The first section is intended for quick reference use for those who are interested in average values. The second section includes data from most of the investigators who have published results on the mechanical properties of copper and its alloys. The third section is composed of tables classifying the investigations which were not included in section two. These usually involve investigations in which data were obtained only at one temperature, such as room temperature. The fourth section lists, in alphabetical order, all references used.

Key Words: Compilation; copper; copper alloys; low temperature; mechanical properties.

Radiochemical analysis: nuclear instrumentation, radiation techniques, nuclear chemistry radioisotope techniques July 1966 through June 1967, Ed. J. R. DeVoe, Tech. Note 421 (Nov. 1967), 50 cents.

This is the fourth summary of progress of the Radiochemical Analysis Section of the Analytical Chemistry Division at the National Bureau of Standards.

The section's effort comprises four major areas: Mössbauer spectroscopy, nuclear chemistry, nuclear instrumentation, and the application of statistics in nuclear and analytical chemistry.

A new design of transducer which is more compact than the previous design has been made so that low temperature experiments can be more easily performed. A method of simultaneously measuring two spectra with a single transducer has been devised. A single line nickel-61 source has been made and the magnetic moment of the excited $5 / 2$ state has been measured with this source. Efforts have continued on the interpretation of the spectral parameters and their relation to structure analysis. Studies are continuing on the production of a standard for chemical shift of tin compounds. 
Equipment is in the final state of assembly and initial testing for measuring cross sections of reactions such as $\left(\gamma,{ }^{3} \mathrm{He}\right)$ or $\left(\gamma,{ }^{4} \mathrm{He}\right)$ by mass spectrometry of the reaction products.

The precision of an analytical method must be carefully used when expressing a detection limit. In addition, care must be taken to be definitive about the meaning of a limit of detection. A suggested procedure for uniformity in reporting these often used terms is presented in this report.

The practical operation of $\mathrm{Ge}(\mathrm{Li})$ and $\mathrm{Si}(\mathrm{Li})$ detectors has been evaluated. It is found that careful control of the preamplifier noise and response is required for optimum performance.

A study of the precision and accuracy of gamma-ray excited x-ray fluorescence was made. Using as a basis the analysis of certified Standard Reference Materials, an improvement of a factor of two in precision was measured. The major advantage concluded from this work is that if rapid analysis requiring portability is desired, the radioisotopic source approach is useful.

Key Words: NBS Linac; computers; standard reference materials; photoneutron reaction; cross sections; flux monitors; nickel-61; Mössbauer spectroscopy; tin standard for chemical shift; PARLORS program for Mössbauer spectra; Mössbauer instrumentation; detection limits for analysis; solid state detectors.

Performance of square-edged orifices and orifice-target combinations as air mixers, T. K. Faison, Jr., J. C. Davis, and P. R. Achenbach, Bldg. Sci. Series 12 (Nov. 24, 1967), 15 cents. A study was made at the National Bureau of Standards to determine the effectiveness of the square-edged orifice, or the orifice in combination with a target (circular baffle), for mixing an air stream which was initially nonuniform with respect to temperature. By achieving uniformity of temperature at all points within the cross section of an air stream, instrumentation for measurement might be simplified and a more representative temperature value obtained. Orifices having throat diameters of 8,12 , and 16 in were evaluated in a 24 -in circular test duct to determine mixing effectiveness under selected test conditions of temperature distribution and flow rate. Targets of 8,12 , and 16 in in diameter in combination with a 12 -in orifice were also investigated under similar conditions.

Graphic material is presented which illustrates how the orifice and orifice-target combinations perform as mixing devices under selected conditions. Results indicate that the 8 -in ( 0.33 diam ratio) orifice effectively diminished the nonuniformity of temperature but only at a high pressure drop across the orifice and that a distance of 4.5 duct diameters was required for mixing.

Key Words: Diameter ratio; mixing effectiveness; square-edged orifice; temperature measurement; temperature pattern.

Selected tables of atomic spectra. Atomic energy levels and multiplet tables Si I, C. E. Moore, NSRDS-NBS 3, Sect. 2, (Nov. 30, 1967), 20 cents.

The present publication is the second Section of a series being prepared in response to the increasing demand for a current revision of two sets of tables containing data on atomic spectra as derived from analyses of optical spectra.

Both the atomic energy levels and the multiplet table are included in the same publication, as parts A and B, respectively. The Sections are being prepared at irregular intervals for these spectra whose analyses are essentially complete. A flexible paging system permits the arrangement of the various Sections by atomic number regardless of the order in which the spectra are published in this series. Section 1 included three spectra of silicon, $Z=14 \pm$ Si II, Si III, Si IV The present Section contains similar data for Si I. The form of presentation is described in detail in the text to Section 1, and need not be repeated here.

Key Words: Atomic energy levels; atomic spectra Si I; multiplet table; silicon, first spectrum; spectrum, Si I; wavelengths, Si I.

Selected values of chemical thermodynamic properties, Tables for the first thirty-four elements in the standard order of arrangement, D. D. Wagman, W. H. Evans, V. B. Parker, I. Halow, S. M. Bailey, and R. H. Schumm, Tech. Note 270-3 (Jan. 1968), \$1.25. (Supersedes Tech. Notes 270-1 and 270-2.)

The tables contain values where known of the enthalpy and Gibbs energy of formation, enthalpy, entropy, and heat capacity at 298.15 ${ }^{\circ} \mathrm{K}\left(25^{\circ} \mathrm{C}\right)$, and the enthalpy of formation at $0{ }^{\circ} \mathrm{K}$, for all inorganic substances and organic molecules containing not more than two carbon atoms, for the first thirty-four elements in the Standard Order of Arrangement.

Key Words: Enthalpy of formation; entropy; Gibbs energy of formation; heat of formation; specific heat; thermodynamic properties.

Tables of bimolecular gas reactions, A. F. Trotman-Dickenson and G. S. Milne, NSRDS-NBS-9 (Oct. 27, 1967), \$2.00.

This survey covers the kinetics of bimolecular and termolecular gas reactions that do not involve atoms or molecules in electronically excited states. Bimolecular reactions are here defined as reactions in which two molecules are involved as reactants, that yield two or more molecules as products. Those reactions in which two molecules combine to form one molecule are most usefully considered as the reverse of unimolecular reactions which will be dealt with in another survey. Reactions of oxygen and nitrogen atoms have been omitted as they will also form the subject of another survey.

The literature from 1954 to December 31,1965 has been exhaustively searched and it is hoped that for this period nothing has been omitted that should have been included.

The survey of earlier work has been based on one of the writers' books on "Gas Kinetics" which covered the literature to 1954. Use of the book for over ten years has revealed few omissions and these have been included in these tables. Data for the period January to August 1966 has been included where possible.

Key Words: Chemical kinetics; gas; bimolecular; reactions; reactions, tables; rate constants; activation energies; Arrhenius equation; data.

Tabulation of data on microwave tubes, J. K. Moffitt, Handb. 104 (Sept. 29, 1967), \$1.25. Supersedes Handb. 70.

A tabulation of microwave electron tubes with characteristics of each type has been arranged in the form of two major listings, a Numerical Listing in which the tubes are arranged by type number, and a Characteristic Listing in which the tubes are arranged by the kind of tube, and further ordered on the basis of minimum frequency and power output.

Key Words: Characteristics tabulation; microwave electron tubes; numerical.

Tabulation of data on receiving tubes, J. K. Moffitt, Handb. 103 (Sept. 29, 1967), \$1.25. Supersedes Handb. 83.

A tabulation of Receiving-Type Electron Tubes with some characteristics of each type has been prepared in the form of two major listings, a Numerical Listing in which the tubes are arranged by type number, and a Characteristic Listing in which the tubes are arranged by tube type and further ordered on the basis of one or two important parameters. The tabulation is accompanied by a listing of similar tube types and basing connections for the listed tubes.

Key Words: Basic connections; characteristics; electron tubes; numerical; receiving-type; similar types; tabulation.

High-precision coulometric iodimetry, G. Marinenko and J. K. Taylor, Anal. Chem. 39, No. 13, 1568-1571 (Nov. 1967).

On the basis of measurement of the potential of the working platinum anode as a function of current density and concentration of KI in solution, conditions were established for $100.0000 \%$ efficient generation of iodine. NBS Standard Reference Material arsenious oxide was analyzed utilizing optimum conditions for generation of iodine and for the stoichiometric reaction of arsenious acid with iodine. The precision of the method for titration of $0.5 \mathrm{~g}$ samples of $\mathrm{As}_{2} \mathrm{O}_{3}$ is about $0.003 \%$. Analysis of data for the assay of samples ranging in size from $100 \mathrm{mg}$ to $\mathrm{lg}$ indicates no bias in the method. Coulometric assay of SRM 83c is $99.986 \pm 0.003 \%$, which is in close agreement with the titrimetric comparison of $83 \mathrm{c}$ to iodine, purified by sublimation. This fact serves as additional evidence of the accuracy of the developed method.

Key Words: Constant-current coulometry; high-precision analysis; iodimetry; arsenious oxide; current efficiency.

Light scattering phenomena near the critical point, D. McIntyre and A. M. Wims (Proc. 2nd Interdisciplinary Conf. 
Electromagnetic Scattering ICES-11, University of Massachusetts, Amherst, Mass., June 28-30, 1965), Book, Electromagnetic Scattering, Ed. R. L. Rowell and R. Stein, pp. 457-484 (Gordon and Breach, Inc., New York, N.Y., 1967).

The scattering from liquids and liquid mixtures near their critical points has been extensively studied in recent years. The existing experimental data are discussed with respect to their usefulness and limitations in sorting out the various statistical mechanical descriptions of critical phenomena. Scattering measurements on polystyrene-cyclohexane, cyclohexane-aniline, perfluoroheptaneisooctane, nitroethane-3-methylpentane are reported and discussed.

Key Words: Critical opalescence; light scattering; critical mixtures; binary mixtures; coexistence curves; phase separations.

Periodic acid, a novel oxidant of polycyclic aromatic hydrocarbons, A. J. Fatiadi, Chem. Communications 21, 1087-1088 (1967).

Certain polycyclic, aromatic hydrocarbons can be oxidized in good yield to quinones with paraperiodic acid in aprotic solvents containing a small proportion of water. No reaction was observed when oxidation was attempted with sodium periodate, instead of periodic acid. A possible reaction path for the oxidation has been suggested.

Key Words: Polycyclic aromatic hydrocarbons; paraperiodic acid; sodium periodate; aprotic solvent; reaction mechanism.

Machine oriented fingerprint classification system, J. H. Wegstein and J. F. Rafferty, Proc. First Natol. Symp. Law Enforcement Science and Technology, March 7-9, 1967, Chicago, Illinois, Ed. S. A. Yefsky, 1, Chapt. V. Information Storage and Retrieval, 459-465 (Academic Press, Inc., New York, N.Y., 1967).

The current state-of-the-art leads one to believe that computers and their associated high-speed mass stores can be utilized in handling large fingerprint files. Toward this end, a single-print classification system is explored. Requirements and objectives are listed. Needed measurements and statistical analyses of variations in details of fingerprints are identified.

Key Words: Fingerprint; automated classification system; ridge endings; bifurcations; minutia; descriptor; identification; Henry System.

Curve-fitting techniques and applications to thermodynamics, J. G. Hust and R. D. McCarty, Cryogenics 7, No. 4, 200-206 (Aug. 1967).

The general problem of least squares fitting is considered. For completeness, derivations of well-known relations are included along with the developments of new techniques for imposing constraints on the unknown parameters, and of fitting data for several different properties simultaneously for both linear and non-linear equations. Several thermodynamic applications are included to illustrate the techniques developed.

Key Words: Curve fitting; least squares; thermodynamics; constraints; weighting; non-linear.

Application of computers to quantitative analysis of microstructures, G. A. Moore, Book, Proc. Second Intern. Congress for Stereology, Chicago, Ill., Apr. 8-13, 1967, Ed. H. Elias, pp. 281-284 (Springer-Verlag, New York, N.Y., 1967).

Stereological projections from any micrograph require evaluation of particle size and shape, thus observation on a dense raster limited only by the resolution of the microscope and observing system. The required large number of observations dictate automatic scanning and computer processing of the image. Results are limited by statistical inefficiency and precision of observation. Using high precision scanning equipment, the inaccuracies of measurement remain comparable to the limits imposed by statistics. Presently attainable precision is, however, an order of magnitude better than can normally be obtained by manual methods.

The presence or absence of a specific phase can be represented by a two-dimensional binary array which can be rapidly processed to yield the required measurements. Logical modification by the computer is frequently necessary to substitute for some of the logical discriminations normally made by the human analyst and to facilitate the desired measurements. Logical processes can reveal stereological relationships, construct morphological models, and dissect and describe the individual particles.
Key Words: Automatic scanning (of micrographs); computer processing (of micrographs); logical modification of pictures; precision scanning (of micrographs); quantitative microscopy; stereological analysis.

The metric system in Illuminating Engineering, L. E. Barbrow, Illum. Engr. LXII, No. 11, 638-640 (Nov. 1967).

The most commonly used unit of illumination in the USA is the footcandle. There are two commonly used units of luminance, the footlambert and the candela per square inch. The growing international adoption of SI units makes it advisable for illuminating engineers to introduce the use of these units in their publications in the immediate future and to understand the implications of the use of the SI units. The SI unit of illumination is the lux (one lumen per square meter). The SI unit of luminance is one candela per square meter (sometimes named the nit). One of the basic principles and advantages of SI is that there can be only one unit for each quantity; thus there cannot be an SI unit similar to footlambert which is expressed in terms of lumens per unit area. Council of the Illuminating Engineering Society has been officially requested to (1) approve the policy of having SI units given primary use in its publications, and (2) promote the depreciation of "lumens per unit area" as a unit of luminance and sponsor its use solely as a unit of luminous exitance (formerly emittance).

Key Words: Exitance; illumination; luminance; lux; metric units; nit; SI units in illuminating engineering.

Contribution of thermal noise to the line-width of Josephson radiation from superconducting point contacts, A. H. Silver, J. E. Zimmerman, and R. A. Kamper, Appl. Phys. Letters 11, No. 6, 209-211 (Sept. 15, 1967).

The line-width of the radio-frequency Josephson oscillation of a voltage-biased superconducting point contact has been measured between 1.3 and $4.2{ }^{\circ} \mathrm{K}$, with bias resistors between $1.7 \times 10^{-10}$ and $2.6 \times 10^{-5} \mathrm{ohms}$. Within the experimental accuracy, the line-width is proportional to RT, the constant of proportionality being of the order of $k / \varphi_{0}^{2}$ (Boltzmann's constant divided by the square of the flux quantum).

Key Words: Thermal noise; Josephson radiation; line-width; superconductivity; point contacts.

Electron diffraction studies of active, passive, and transpassive oxıde films formed on iron, C. L. Foley, J. Kruger, and C. J. Bechtoldt, J. Electrochem. Soc. 114, No. 10, 994-1001 (Oct. 1967)

Iron foil specimens were anodically polarized by means of a potentiostat in $1 \mathrm{~N} \mathrm{H}_{2} \mathrm{SO}_{4}, 0.1 \mathrm{~N} \mathrm{NaOH}$ and a sodium borate boric acid solution $(\mathrm{pH}, 8.5)$. Both passive, active and transpassive regions of the polarization curve were studied for each solution. The oxide films were examined while still in contact with the iron foil by selected area transmission electron diffraction. Five iron planes were studied: $\{100\},\{110\},\{111\},\{210\}$ and $\{211\}$, and the epitaxial relationship of the oxide to the iron substrate determined. Evidence was found indicating that in all of the electrolytes used the passive film contained $\gamma-\mathrm{Fe}_{2} \mathrm{O}_{3}$, while the non-passive films did not.

Key Words: Electron diffraction; gamma- $\mathrm{Fe}_{2} \mathrm{O}_{3}$; iron; passivation.

Negative dispersion and brillouin scattering, R. D. Mountain and T. A. Litovitz, J. Acoust. Soc. Am. 42, No. 2, 516-517 (Aug. 1967). The fluctuations in density observed in Brillouin scattering may be represented as temporally absorbed waves. Negative dispersion occurs for these waves although it may be masked by positive dispersion due to relaxation processes. Numerical estimates of velocity and of negative dispersion are made for $\mathrm{CCl}_{4}$ at $20^{\circ} \mathrm{C}$. The importance of measuring both the position and the width of the Brillouin peaks in order to obtain the elastic modulus of the liquid is stressed.

Key Words: Brillouin scattering; elastic modulus; liquid; negative dispersion relaxation of viscosity; temporal absorption.

Response of pneumatic pressure-measurement systems to a step input in the free molecule, transition, and continuum flow regimes, J. Hord, ISA Trans. 6, No. 3, 252-260 (July 1967).

A simplified analysis of the response of pressure-sensing devices and their interconnecting tubing is presented. The results are 
conveniently presented in the form of time equations, with the fractional change in the applied step (usually $63.2 \%$ ) as the variable. A single algebraic equation adequately predicts (within about $\pm 20 \%$ ) the response of simple pressure-measuring systems in the free molecule, transition and continuum flow regimes. Two very simple algebraic equations (for free molecule and continuum flow) may be used to predict time response throughout the flow regimes if a maximum error of about 2:1 (predicted time constants are 2 times too large) is tolerated in the mid-transition range. The criterion is given for extension of these formulae into the transition flow range. The formulae are limited to relatively small pressure steps in the viscous flow region (Poiseuille flow) and are not restricted for free molecule flow. All of the formulae developed are suitable for field engineering applications. The existing literature is synthesized by comparison with the analysis. The relative importance of the numerous variables encountered in this type of analysis is discussed.

Key Words: Response of pneumatic pressure-measurement systems in the free molecule, transition, and continuum flow regimes; response of pneumatic pressure-sensing tubulation; response of pneumatic transmission lines; time constants of pneumatic pressure lines; time lag and delay in pneumatic pressure-sensing lines; time respons of pneumatic pressure-sensing systems to step inputs.

Diminishing discoloration in methacrylate accelerator systems, R. L. Bowen and H. Argentar, J. Am. Dental Assoc. 75, No. 4, 918-923 (Oct. 1967).

A method was devised for accentuating the formation of discoloration products that may form during the free radical polymerization of methacrylates at room temperature. Various accelerators and stabilizers were compared on an equimolar basis. The selection of the materials was based on literature information regarding current theories of free radical polymerization and the absorption of visible light by organic compounds. The use of the sterically hindered phenol, butylated hydroxytoluene, did not produce discoloration whereas, the use of hydroquinone or the monomethylether of hydroquinone had a darkening effect. A compound (N,N-dimethyl-3, 5-dimethylaniline) was synthesized which was an effective accelerator and which produced less discoloration than did N,N-dimethyl-p-toluidene.

Key Words: Color formation; discoloration; methacrylate; polymerization: N,N-dimethyl-3, 5-dimethylaniline; accelerators.

Metallo-organic polymers, E. Horowitz, Mod. Plastics 45, No. 3 , 146-148 (Nov. 1967).

Certain organic molecules containing electron-donating groups such as derivatives of bis( $\beta$-hydroxyquinoline) can be reacted with metal ions to yield metallo-organic polymers in which the meta atoms are linked in the backbone. Both linear and cross-linked polymers have been prepared and their thermal stabilities have been investigated. It has been shown that the thermal stability of these polymers is related to the properties of the metal and the composition of the organic component.

Key Words: Metallo-organic polymers; synthesis; thermal stability; role of metal and ligand.

Thermal titration of platinum black and the initial heat of adsorption for hydrogen, E. S. J. Tomezsko and G. T. Furukawa, J. Catalysis 8, No. 4, 386-388 (Aug. 1967).

The heat of adsorption of hydrogen on platinum black was investigated by means of an automatically controlled adiabatic calorimeter. When the platinum black was carefully freed of adsorbed oxygen, no rapid decrease was observed in the heats of adsorption with increasing coverage of hydrogen. The heat of adsorption of hydrogen on clean platinum surface was found to be $17.5(73.2 \mathrm{kv} / \mathrm{mole}) \mathrm{kcal} / \mathrm{mole}$ of hydrogen, with an estimated uncertainty of $\pm 0.2 \mathrm{kcal} / \mathrm{mole}$ $( \pm 0.8 \mathrm{kv} / \mathrm{mole})$.

Key Words: Adsorption of hydrogen on platinum black; heat of adsorption of hydrogen; platinum black; thermal titration.

Volume changes accompanying collagen denaturation, R. G. Christensen and J. M. Cassel, Biopolymers 5, 685-689 (1967). A dilatometric technique is employed to measure the volume changes occurring on denaturation of collagen solutions and tendons. Partial specific volumes of tropocollagen are calculated to be $0.686 \mathrm{ml} / \mathrm{g}$ in water and $0.689 \mathrm{ml} / \mathrm{g}$ in $0.1 \mathrm{M}$ citrate buffer. From data on nonaqueous solutions, it is estimated that most of the volume change arises from changes in polymer configuration rather than from changes in solvation.

Key Words: Partial specific volume; collagen; dilatometry; denaturation; solvation; hydration.

Development of a method for testing and rating refrigerated truck bodies, C. W. Phillips and R. W. Penny, USDA Tech. Bull. No. 1376 (Superintendent of Documents, Government Printing Office, Washington, D.C. 20402, Sept. 1967, 15 cents).

A recommended standard method is presented for testing and rating the cooling load due to heat transmission and air and moisture leakage into refrigerated truck bodies used for stop and go delivery of perishable chilled or frozen food. Results of laboratory tests of five typical vehicles, with and without simulated solar heating, were used as a basis for determining criteria for the testing and rating procedure. A steady-state test procedure, with appropriate multipliers to account for solar heating is recommended. Rating conditions of $0{ }^{\circ} \mathrm{F}$ and $35^{\circ} \mathrm{F}$ interior temperature and $100{ }^{\circ} \mathrm{F}$ and 50 percent ambient temperature and relative humidity are suggested. Means for calculating air leakage rate from observed weight gain rate under standard test conditions are incorporated. Measurement of service cooling loads caused by warm cargo or by air exchange through opening and closing of doors is not included in the recommended procedure. However, such service loads must be considered in determining the capacity of an adequate refrigeration system.

Key Words: Rating and testing; cooling loads; refrigerated truck bodies; simulated solar heating; weight gain; air leakage.

Experimental apparatus and procedures for evaluating parameters affecting the pumping efficiency of a cryogenically cooled plane, L. O. Mullen and M. J. Hiza, J. Vacuum Sci. Technol. 4, No. 5, 219-229 (Sept.-Oct. 1967).

The collection efficiency of a plane acting as a pump in a vacuum system can be determined by measuring the rate at which molecules of a given species strike and the rate at which they return from that plane. This paper discusses an experimental vacuum system incorporating a moveable partial pressure analyzer capable of making such measurements. The experimental procedure discussed here provides a means for evaluating parameters affecting the pumping efficiency. Efficiency values obtained by the present approach are compared with values obtained from kinetic theory and from speed factor measurements. The experimental data show that much of the deviation of reported pumping efficiencies can be explained by fragmentation of the test gas molecules and by a pressure anisotropy in the test dome. A means of calibrating the analyzer with vapor pressure data is also discussed.

Key Words: Capture coefficient; cryocondensation; cryogenically cooled surfaces; cryopump; partial pressure measurements; pressure calibration with vapor pressures; pressure anisotropy; pumping efficiency; pumping speed; speed factor measurements; sticking coefficient; vacuum techniques.

Improving pressure and vacuum measurement standards, E. C. Lloyd, Instr. Control Systems 40, No. 9, 105-109 (Sept. 1967). Results of the NBS developments are outlined in a number of projects relating to standards for improved measurement of pressures throughout the range from vacuum to very-high pressures. In the vacuum range this includes techniques for generation of stable reference pressures, and improved absolute instruments for force per unit area measurement down to $10^{-9}$ torr. In the range from a few millibars to hundreds of kilobars the use of fixed points, and the performance of improved piston gages and interpolation instruments, are described. Problems presently limiting accuracy of calibration and NBS investigations of possible solutions are mentioned. Two new "accuracy charts" are presented showing present and possible future NBS capabilities.

Key Words: standards; calibration; measurement, pressure; vacuum; accuracy.

Configuration of isolated polymer molecules adsorbed on solid surfaces studied by Monte-Carlo computer simulation, 
F. L. McCrackin, J. Chem. Phys. 47, No. 6, 1980-1986 (Sept. 15, 1967).

The configurations of adsorbed polymer molecules with excluded volume were simulated on a four-choice simple cubic lattice using a computer. The average values of the fraction of segments on the surface, loops off the surface, normal distance of the end of the molecule from the surface, root-mean-square of the normal distance, maximum normal distance from the surface, and root-mean-square end-to-end distance were calculated for various lengths of the molecules and attractive energies to the surface. When these averages over the configurations are compared with previous results which had neglected the excluded volume effect and important differences are found.

Key Words: Adsorption; configurations; four-choice cubic lattice; Monte Carlo; polymers.

Ears on the line profile of decay transitions in a gas laser, W. G. Schweitzer, Jr., M. M. Birky, and J. A. White, J. Opt. Soc. Am. 57, No. 10, 1226-1230 (Oct. 1967).

In a gas laser a spectrum line whose upper state is the lower state of the laser transition may contain a structure due to the laser action. We have observed this structure, which we refer to as ears, on the $6096 \AA$ Neon line emitted spontaneously in a $1.15 \mu \mathrm{m} \mathrm{He}-\mathrm{Ne}$ laser. The width of the ear was measured interferometrically and compared with the width predicted from the phenomenological width $\gamma_{a b} / \pi$ in the laser transition.

Key Words: Laser; line profile; lifetime; neon.

Nuclear magnetic resonance in sodium thallide, L. H. Bennett, Acta. Met. 14, No. 8, 997-999 (1966).

The nuclear magnetic resonance signal for $\mathrm{Ti}^{203,205}$ is observed in sodium thallide alloys. It is determined that the previously reported negative Knight shift value of one percent for NaTl was essentially correct, and the more recently reported negative value of one-half percent was in fact for $\mathrm{NaTl}_{2}$. A crystal structure is proposed for $\mathrm{NaTl}_{2}$.

Key Words: Nuclear mangatic resonance; sodium; thallium; alloys; intermetallic; compounds; x-ray diffraction; Knight shift.

Nuclear Magnetic resonance in zintl intermediate phases LiCd and LiZn, L. H. Bennett, Phys. Rev. 150, No. 2, 418-420 (Oct. 1966).

The nuclear magnetic resonances have been observed for $\mathrm{Li}^{7}$ and $\mathrm{Cd}^{113}$ in $\mathrm{LiCd}$ and for $\mathrm{Li}^{7}$ and $\mathrm{Zn}^{67}$ in $\mathrm{LiZn}$. The Knight shift for $\mathrm{LiCd}^{113}$ is $0.39 \%$ for $\mathrm{LiZn}^{67} 0.20 \%$, for $\mathrm{LiCd}$ or LiZn less than $0.01 \%$. An energy band scheme is proposed.

Key Words: Zintl phase; LiCd; LiZn; $\beta$-32 structure; nuclear magnetic resonance; Knight shifts, linewidths.

Nuclear quadrupole resonance thermometry, D. B. Utton, Metrologia 3, No. 4, 98-105 (Oct. 1967).

The nuclear quadrupole resonance frequency of ${ }^{35} \mathrm{Cl}$ in $\mathrm{KClO}_{3}$ has been studied in the temperature range $12{ }^{\circ} \mathrm{K}-297^{\circ} \mathrm{K}$. The combined uncertainties in the frequency and temperature measurements correspond to $\pm .001{ }^{\circ} \mathrm{K}$ in the range $50{ }^{\circ} \mathrm{K}-297^{\circ} \mathrm{K}$, deteriorating to $\pm .004^{\circ} \mathrm{K}$ at $30^{\circ} \mathrm{K}$ and $\pm .010^{\circ} \mathrm{K}$ at $20^{\circ} \mathrm{K}$. Both the nuclear resonance spectrometer and the temperature control apparatus are described. The experimental data are fitted to a theoretical expression in the temperature range $12{ }^{\circ} \mathrm{K}-90{ }^{\circ} \mathrm{K}$; at higher temperatures the data are fitted to empirical polynomials.

Key Words: Nuclear quadrupole resonance thermometry $12{ }^{\circ} \mathrm{K}-$ $297^{\circ} \mathrm{K}$; potassium chlorate; instrumentation.

Sapphire window mountings for low temperature spectroscopy, L. J. Schoen, Rev. Sci. Instr. 38, No. 10, 1531-1532 (Oct. 1967).

Two newly designed sapphire window mountings suitable for use at cryogenic temperatures are described. These should prove valuable in maintaining efficient, reproducible and trouble free thermal contact with conventional refrigerants.

Key Words: Cryostat; deposit; thermal contact; thermal conductivity; window holder.
Stochastic theory of multistate relaxation processes, I. Oppenheim, K. E. Shuler, and G. H. Weiss, Adv. Mol. Relaxation Processes 1, No. 1, 13-68 (Nov. 1967).

The stochastic theory of multistate relaxation processes is discussed with special reference to Markov Processes, the derivation and properties of the Master Equation, the derivation and properties of the Fokker-Planck Equation and First Passage Time problems. The theory developed is then applied to a number of examples.

Key Words: Stochastic processes; relaxation processes; markov processes; Fokker-Planck equation; master equation; first passage times.

Transitions in vapor-deposited alumina from 300 to $1200{ }^{\circ} \mathrm{C}$, A. L. Dragoo and J. J. Diamond, J. Am. Ceramic Soc. 50, No. 11 , 568-574 (Nov. 1967).

The transition of amorphous alumina to $\alpha$-alumina was studied by x-ray diffraction, electron diffraction, DTA, TGA, and microscopic observation. The amorphous alumina was prepared by evaporation of molten alumina in vacuo and its deposition on the glass envelope of the vacuum chamber. Two transition paths were observed after the amorphous alumina passed through an initial crystallization region (between 570 and $670{ }^{\circ} \mathrm{C}$ at 16 hours). The principle sequence was $\gamma$-, to $\delta$ - to $\alpha$-alumina. A minor amount of $\theta$-alumina developed from the initial crystallization and persisted throughout the duration of the former sequence as a parallel path. Some conversion of $\delta$ - to $\theta$-alumina was detected above $900{ }^{\circ} \mathrm{C}$. DTA produced an unexplained exothermic peak at $320^{\circ}$ and a second exothermic peak at $860^{\circ}$ which corresponded to formation of metastable aluminas.

Key Words: Alumina, alpha alumina, amorphous alumina, delta alumina, gamma alumina, intermediate aluminas, metastable aluminas, phase transitions, theta alumina

Lunar tides in the ionosphere, S. Matsushita, Encyclopedia of Physics XLIX/2, 547-602 (Springer-Verlag, Berlin, Germany, 1967). All previous work on lunar tidal variations in the ionospheric F2, F1, E, Es, and D layers by various researchers are thoroughly reviewed and are compared with recent results of lunar tides obtained from ionospheric electron density profile data and also with radio observations of lunar tidal winds in the ionosphere. A world-wide behavior of the lunar tides in different ionospheric layers is then obtained. After reviewing lunar tidal variations in the surface atmosphere, geomagnetic lunar variations at several places are examined, and a new lunar current system at about $100 \mathrm{Km}$ altitude is suggested. Based on this current system the lunar tides in the ionosphere are discussed theoretically, taking into consideration both hydro and electro dynamical motions.

Key Words: Ionosphere; lunar tides; lunar variations; surface atmospheres.

Analysis of gold and platinum group alloys by $x$-ray emission with corrections for interelement effects, J. D. Eick, H. J. Caul, D. L. Smith, and S. D. Rasberry, Appl. Spectry. 21, No. 5, 324-328 (Sept.-Oct. 1967).

The x-ray emission analysis of noble metal alloys was investigated critically to determine optimum conditions for accurate analysis. The analytical curves for the elements $\mathrm{Cu}, \mathrm{Pd}, \mathrm{Pt}$, and $\mathrm{Zn}$ were found to be linear with a deviation of less than \pm 0.2 percent. However, a nonlinear relationship existed for gold and for silver. These discrepancies could not be eliminated by variation in sample preparation. An interelement effect due to $\mathrm{x}$-ray absorption and enhancement was found and was corrected to an accuracy of 0.2 percent by means of a mathematical treatment suggested by Lucas-Tooth and Price. The analysis by $\mathrm{x}$-ray emission can be accomplished in approximately one-tenth of the time necessary for conventional wet chemical methods.

Key Words: Gold and platinum group alloys; noble metal alloys; $\mathrm{x}$-ray emission.

Chemical changes induced by high energy radiation. The present state of our knowledge, P. Ausloos, Scientia CII, 1-14 (Sept.-Oct. 1967).

The chemical changes in matter brought about by absorption of low energy radiation such as visible and ultraviolet light have been intensively investigated for several decades. On the other hand, the 
chemical transformations induced by high energy radiation $(\mathrm{X}$, gamma, $\beta, \alpha$-rays) were long considered to be of such complexity that the task of unravelling them was considered insurmountably difficult. However, during the last decade, impressive advances have been made towards achieving an understanding of the fundamental chemical processes induced by high energy radiation. Many experimental techniques, some of which are new and some of which have been used in other areas of physics or physical chemistry, have now been brought to bear on the problem. Through these various approaches definitive information has been obtained concerning the existence and reactions of the various highly reactive intermediate species (radicals, ions, excited molecules produced by high energy radiation). The understanding of such systems has now reached a degree of sophistication such that high energy radiation can be used to obtain accurate information about various well defined chemical and physical processes which are of general scientific interest.

Key Words: High-energy radiation; chemical changes; ion-molecule reactions; free radical reactions.

Criteria for selection of absorber mounting materials in Mössbauer spectroscopy, L. May and D. K. Snediker, Nucl. Instr. Methods 55, 183-188 (1967).

The criteria for the selection of materials for mounting absorbers include their mechanical and chemical properties and their attenuation of the $\gamma$-rays and X-rays emitted from the Mössbauer source. Attention of the $14.4-\mathrm{keV} \gamma$-ray and $6.3-\mathrm{keV} \mathrm{X}$-ray associated with ${ }^{57} \mathrm{Fe}$ was measured for nine commercial materials including plastics and metals. The linear absorption coefficients and half-thicknesses for each material were measured. The usefulness and limitations of each material are discussed, along with three different absorber mounting techniques.

Key Words: Absorber mounting devices; absorption coefficients; gamma-rays and x-rays; half-thickness; Mössbauer spectroscopy; 14.4-keV.

Determination of medium-weight elements by gamma-excited x-ray fluorescence, M. G. Hollstein and J. R. DeVoe, (Proc. Second Symp. on Low Energy X-and Gamma Sources and Applications, University of Texas, Austin, Texas, Mar. 27-29, 1967), ORNL-IIC-10, pp. 483-502 (1967).

The application of gamma-excited $\mathrm{x}$-ray fluorescence in the determination of medium weight elements has been studied. The pertinent components of the spectrometer are an ${ }^{241} \mathrm{Am}$ source and a solid state detector, with a low-noise preamplifier and multi-channel analyzer. The resolution of the system is between 1.2 and $1.3 \mathrm{keV}$ (FWHM) for 8 to $45 \mathrm{keV}$ photons. Three different techniques of sample mounting were investigated. For single elements in the range from $\mathrm{Cu}$ to Dy the estimated detection limits are $10-100 \mu \mathrm{g}$ and 0.01-1 $\mathrm{mg} / \mathrm{ml}$, depending upon the sample mounting procedure. The corresponding $\mathrm{K}_{\alpha}$-peak intensities are $2 \times 10^{4}-3 \times 10^{3} \mathrm{cpm}$ per $\mathrm{mg}$ and $4 \times 10^{4}-6 \times 10^{2} \mathrm{cpm}$ per $\mathrm{mg} / \mathrm{ml}$, respectively. For testing the application of the method two series of NBS Standard Reference Materials were analyzed for Sn and Mo as minor constituents within a concentration range from about 0.04 to $9 \%$. The best results were obtained by direct counting of the solid samples. Using this technique, a non-destructive analysis for Mo and $\mathrm{Sn}$ can be performed in a relatively short time with a precision of a few percent, a detection limit of about $100 \mathrm{ppm}$ and a sensitivity of $6 \times 10^{3}$ to $1.4 \times 10^{4} \mathrm{cpm}$ per percent concentration.

Key Words: Quantitative analysis; tin; molybdenum; medium weight elements; X-ray fluorescence; gamma-excitation.

Evaluation procedures and annual performance data for Leclanché cells, W. J. Hamer, Electrochem. Technol. 5, No. 11-12, 490-498 (Nov.-Dec. 1967)

This paper deals with the development over the past 48 years of so-called "standardized tests" for the evaluation of Leclanché cells and batteries. Data covering this time period or a part of this time period are given for (1) general-purpose flashlight cells, (2) industrial flashlight cells, (3) railroad lantern batteries, (4) photoflash cells, (5) No. 6 cells for various end uses, (6) radio " $A$ " batteries, (7) radio "B" batteries, (8) hearing-aid "A" batteries, (9) hearing-aid "B" batteries, and (10) transistor hearing-aid batteries. The presently used standard tests, 27 in number, are described. A history of the development of dry cells of the Leclanché type is also included.
Key Words: Dry cell tests, dry cell standards; battery nomenclature; advances in dry cells; dry cell specifications; international dry cell standards.

Glass-membrane potentials in mixed anion melts, K. H. Stern, J. Electrochem. Soc. 114, No. 12, 1257-1258 (Dec. 1967).

The emf of the four-ion concentration cell with membrane

$$
\mathrm{Ag}\left|\mathrm{Ag}^{+}, \mathrm{Na}^{+}, \mathrm{Cl}^{-}, \mathrm{Br}^{-}\right| \text {glass }\left|\mathrm{Ag}^{+}, \mathrm{Na}^{+}, \mathrm{Cl}^{-}, \mathrm{Br}^{-}\right| \mathrm{Ag}
$$

is derived for the case $\mathrm{X}_{\mathrm{Na}+} \ll \mathrm{X}_{\mathrm{Ag}+}$ by assuming that the cationic chemical potentials are additive functions in the mole fractions of the thermodynamic components, e.g., $\mu_{\mathrm{Ag}+}=\mathrm{X}_{\mathrm{AgCl}} \mu_{\mathrm{AgCl}}+\mathrm{X}_{\mathrm{AgBr}} \mu_{\mathrm{AgBr} r}$. For solutions very dilute in sodium, corrections for non-ideality are negligible. Experimental results agree satisfactorily with calculated ones.

Key Words: Molten salts; galvanic cells; membrane potentials.

Multiplex for dual-spectrum Mössbauer spectrometry, F. C. Ruegg, (Proc. Second Symp. on Low Energy X-and Gamma Sources and Applirations, University of Texas, Austin, Texas, Mar. 27-29, 1967), ONRN-IIC-10, pp. 157-175 (1967).

It is often desirable to have the capability of accumulating two Mössbauer spectra simultaneously with both spectra having exactly the same Doppler velocity dependence. This is possible with a multiplexing system which allows accumulation of two spectra simultaneously and storing of each spectrum in a 200 channel subgroup of a multichannel analyzer. The memory of the analyzer which is operated in the time mode is used on a demand basis by the two detector systems, and the counts are routed to the proper subgroup in complimentary channel locations, i.e., the channel location in the second subgroup is the channel number in the first sub group plus 200. The logic, circuitry and performance are described.

Key Words: Multiplex; Mössbauer; dual spectra; spectroscopy.

New developments in zinc oxide-eugenol cement, G. M. Brauer, Ann. Dentistry 26, No. 2, 44-50 (1967).

During the last few years considerable interest has been generated in improving zinc oxide-eugenol materials. A better understanding of the setting mechanism of these cements has become available which has lead to the development of modified ZOE cements usually containing o-ethoxy-benzoic acid (EBA). These materials show reactions to the tissues including the dental pulp similar to $\mathrm{ZOE}$ cements. Physical properties of the EBA containing cements approach those of the biologically less desirable zinc phosphate cements.

Key Words: EBA cements; zine oxide eugenol cements; dental materials; dental cements; new developments in dental materials.

Pertinent data on some physical properties of differen" investments used in the casting of gold alloys, M. Ohashi, J. W. Stanford, and G. C. Paffenbarger, J. Nihon Univ. Sch. Dent. 9, No. 3, 121-126 (Sept. 1967).

Fineness, time of setting, compressive strength, linear thermal expansion, hygroscopic expansion, normal setting expansion, and surface defects of alloy castings were determined using casting investments of three types thermal inlay, hygroscopic inlay, and thermal partial denture. The use of the normal setting expansion combined with either the hygroscopic or thermal expansion to compensate for the shrinkage of casting gold alloys is discussed.

Key Words: Alloy castings; gold alloys; hygroscopic inlay; thermal inlay; thermal partial denture.

Qualitative and quantitative determination of emulsionpolymerised binders in latex paints, M. A. Post, J. Appl. Chem. 17, 315-320 (Nov. 1967).

Methods for the separation and identification by infrared absorption spectroscopy of styrene-butadiene, acrylic, vinyl-acrylic and polyvinyl acetate homopolymer and dibutyl maleate copolymer in emulsion paints based on these materials are presented. Detailed procedures for their quantitative determination are discussed.

Key Words: Acrylic; identification; infrared spectroscopy; latex paints; polyvinyl acetate; separation; styrene-butadiene; vinylacrylic. 
A flattery index for artificial illuminants, D. B. Judd, Illum. Eng. 62, No. 10, 593-598 (Oct. 1967).

Artificial illuminants are used for (1) light-dark discrimination of objects, (2) critical appraisal of colored objects, and (3) appreciative viewing of colored objects. A light source that renders object colors in accord with their preferred colors may be said to flatter those objects. A flattery index has been derived for light sources used for appreciative viewing of colored objects to measure the degree to which such sources render object colors as we would like to see them. This index is based solely on spectral distribution and is modeled after the index of color rendition recently recommended by the CIE. It uses 10 of the 14 test samples established for appraisal of color rendition, and it uses the same definition of reference illuminants. It is scaled so that the reference illuminant receives a flattery index of 90, and a test illuminant rendering object colors precisely in accord with the preferred colors of the test samples receives a flattery index of 100 . The test sample representative of the human complexion receives about one-third of the total weight; the two test samples representative of food colors, about one-third; the seven other test samples, the remainder.

Key Words: Color; flattery; illuminants; preference; rendition of color.

An analysis of the "quarter-wave" technique of reducing the errors in UHF and microwave impedance measurement, W. E. Little, D. A. Ellerbruch, and G. F. Engen, IEEE Trans. Microwave Theory Tech. MTT-15, No. 9, 504-507 (Sept. 1967).

An analysis is given of the "quarter-wave" impedance measurement technique. This technique, which finds its widest potential application in conjunction with standing wave machines, permits the approximate elimination of the error due to residual reflection or VSWR. If the other sources of error are small, the potential reduction in error is in the ratio $\left|t_{11}\right| / 2\left|S_{11}\right|$, where $S_{11}$ and $t_{11}$ are the residual reflection coefficients of the standing wave machine and quarter wavelength section respectively.

Key Words: Impedance measurement; reflection coefficient measurement; quarter wave; standing wave machine; UHF; microwave.

Accelerometer resonances affect vibration measurement, E. T. Pierce, O. W. Price, S. E. Edelman, and E. Jones, J. Environ. Sci. 10, No. 6, 17-21 (Dec. 1967).

Errors in vibration measurement can be caused by unintended relative motion in the pickup. Near the resonant frequency of such relative motion, the pickup can affect the motion of surface to which it is attached. The paper gives details of two cases of resonances of this kind; resonances which are unexpected on the basis of the usual mass-spring theory.

Key Words: Accelerometer; resonance; vibration; pickup; calibration.

Preparation of electron probe microanalyzer standards using a rapid quench method, J. I. Goldstein, F. J. Majeske, and H. Yakowitz, Advan. X-ray Anal. 10, 431-446 (1967).

Standards for microprobe analysis can be made to serve two purposes: (1) Proposed correction models acan be tested with them and (2) Analysis can be performed more accurately in the system which includes the standard. Few microprobe standards are presently available because they must be homogeneous on the micron scale and their composition must be known accurately. A modified Duwez splat cooling method is described which enables the investigator to prepare suitable standards in most cases. The apparatus which is relatively simple and inexpensive is described in detail. The systems Au-Si and $\mathrm{Al}-\mathrm{Mg}$ were chosen as test cases. Suitable standards were prepared at different concentrations in each system. The analytical results for all compositions in $\mathrm{Al}-\mathrm{Mg}$ are presented and discussed.

Key Words: Al-Mg; Au-Si; electron probe standards; quantitative microanalysis; standard preparation; splat cooling.

The National Bureau of Standards program in computer sciences and technology, H. R. J. Grosch, Stat. Reptr. 68-3, 37-41 (Superintendent of Documents, Government Printing Office, Washington, D.C. 20402, Sept. 1967, 20 cents).

The NBS Center for Computer Sciences and Technology was established in 1965 to perform the Bureau's work in the field of computer technology - a broad program of standardization activities, applied research, and services to Federal agencies. Work on standards includes that on USASCII (for use in Federal procurement, under the terms of the Brooks Bill of October 1, 1965) and on optical character recognition. Services to other branches of government include providing data processing services, computational assistance, and consultation. The activities of the center's Technical Information Exchange and the continued experimentation with computers will have industry-wide benefits.

Key Words: Brooks Bill; computer standards; computer technology; data processing; government.

Midpoint quadrature formulas, S. Haber, Math. Compt. 21, No. 100, 719-721 (Oct. 1967).

A family of quadrature formulas for the interval $(0,1)$ can be defined by partitioning the interval into subintervals and taking as nodes the midpoints of these intervals, with the lengths of the intervals serving as coefficients. The errors of these formulas are determined.

Key Words: Numerical analysis; quadrature; integration; computing.

The HAYSTAQ experiment, H. W. Hayward and S. J. Tauber, Proc. ICIREPAT Fifth Annual. Meeting, London, England, Aug. 31Sept. 10, 1965, Chapt. 26, pp. 337-350 (Thompson Book Co., Washington, D.C., 1967).

The background of the HAYSTAQ system is recapitulated. Shortcomings of an earlier chemical structure representation are reviewed; the scope and some advantages of the Hayward notation are stated. Suggestions are made for representing mixtures and classes of compounds. The scope is stated of notations for classes of reactions. The organization of files of chemical information and patterns of retrieval are discussed. Capabilities, limitations, and future implications of the techniques evolved are pointed out.

Key Words: Chemistry; compounds; computer; file organization; HAYSTAQ; Hayward; information retrieval; linear notation; Markush; mixtures; reactions; representations; screens; structures; topological codes.

Spectral irradiances as determined through the use of prism and filter spectroradiometric techniques, W. E. Schneider, R. Stair, and J. K. Jackson, Appl. Opt. 6, No. 9, 1479-1486 (Sept. 1967).

Two spectroradiometers, one based on a conventional prism monochromator and the other on a system employing narrow band-pass interference filters, have been set-up and independently used in the determination of the spectral irrandiances of a number of sources over the wavelength range $0.25 \mu \mathrm{m}$ to $2.5 \mu \mathrm{m}$. Basically, the method of calibration for each system consists of comparing the spectral irradiance of the source under investigation to that of an NBS standard of spectral irrandiance. The results obtained with each system on a number of "continuous" sources agree to about one percent whereas the differences in the spectral irradiances obtained with the two-set-ups on a number of line sources range up to several percent.

Key Words: Radiometry; spectral irradiance; prism-spectroradiometer; filter-spectroradiometer; measurement techniques; sources.

Anomalous heat capacity of TiNi, H. A. Berman, E. D. West, and A. G. Rozner, J. Appl. Phys. 38, No. 11, 4473-4476 (Oct. 1967). Calorimetric measurements on a sample of TiNi $(50$ atomic percent Ti) show that the heat-capacity maximum at approximately $87{ }^{\circ} \mathrm{C}$ represents a higher-order transition. The transition was shifted to lower temperatures each time the material was heated through the transition from slightly above room temperature to about $150-200^{\circ} \mathrm{C}$. The transition enthalpy decreased in three such cycles from 4150 to $3375 \mathrm{~J} /$ mole TiNi.

Key Words: Titanium-nickel heat capacity; titanium-nickel phase transition.

Correlation measurement in a turbulent flow using highspeed computing methods, F. N. Frenkiel and P. S. Klebanoff, Phys. Fluids 10, No. 8, 1737-1747 (Aug. 1967).

Third-order time-correlations downstream of a grid were measured with a hot-wire anemometer using high-speed computing methods. 
The nonlinear response of the hot-wire to the fluctuations of velocities is taken into account as well as the effect of transverse velocities. It is found that the third-order correlations are substantially different from previous results and demonstrate that the assumption of isotropy is not adequate for these correlations downstream of a grid. The nonlinear response does not significantly affect the difference $\overline{u_{1}^{2} u_{2}}-\overline{u_{1} u_{2}^{2}}$. Since previous conclusions concerning the nature of third-order correlations were based on the measurements of such differences they masked the effects of nonlinearity on the individual correlations. Correlations of fifth-order are also presented and their relations to the third-order correlation are discussed. Although the nonlinear corrections are quite important for odd-order correlations they are negligible for correlations of even-order.

Key Words: Turbulence; grid; hot-wire anemometer; nonlinear response; correlations; odd-order; even-order; isotropy.

Effect of a sinusoidal excitation amplitude on the performance of an atomic-beam spectrometer, J. H. Shirley, Phys. Rev. 160, No. 1, 95-99 (Aug. 5, 1967).

A theoretical analysis has been made of the transition probabilities for a Rabi-type atomic beam spectrometer in which the exciting field amplitude seen by the atoms has a sinusoidal rather than a rectangular envelope. The time-dependent Schrödinger equation was integrated numerically and a velocity average of the transition probabilities performed. The results indicate that the line width increases as the fourth root of the excitation power and that frequency shifts due to coupling of the exciting field with other atomic states can be reduced by an order of magnitude.

Key Words: Atomic beam; transition probability; velocity average; frequency shift; Rabi spectrometer; Schrödinger equation.

Ellipsometric-potentiostatic studies of iron passivity, I Anodic film growth in slightly basic solutions, J. Gruger and J. Calvert, J. Electrochem. Soc. 114, No. 12, 1265-1267 (Dec. 1967). Cathodically reduced iron was anodically oxidized to potentials in the passive region of the anodic polarization curve at passive potentials in nearly neutral sodium borate-boric acid solutions by means of a potentiostat. The kinetics of film growth were studied using an ellipsometer coupled with a high speed recording technique, which enabled a determination of the rate of film formation for times less than one second. This study of the kinetics of film growth using a non-electrochemical technique agreed with kinetic results based on total charge measurements.

Three states of growth were detected: (1) First Stage-growth limi ted by the diffusion of oxidizing species through solution. (2) Second Stage - start of limitation of growth of film. A combination of severa processes difficult to characterize by any rate law. (3) Third Stagegrowth obeying either a direct or indirect logarithmic rate law. The latter was found to imply that the passive film consisted of an outer layer poorly conductive for electrons.

Key Words: Ellipsometry; potentiostat; anodic oxidation; kinetics; iron oxide films; iron and passivity.

Laser harmonics useful for frequency translation, W. S Lovell, M. M. Anderson, and F. E. Seiller, Appl. Opt. 6, No. 8, 1430-1432 (Aug. 1967).

Accidental coincidences between laser fundamental and harmonic frequencies usable (in principle) for frequency translation are tabulated.

Key Words: Laser harmonics; frequency translation; accidental coincidences; frequency locking.

Some techniques used in the study of stress corrosion cracking, H. L. Logan, Am. Soc. Testing Mater. Stress Corrosion Testing Spec. Tech. Publ. 425, 127-144 (1967).

Techniques used at the National Bureau of Standards in the study of stress-corrosion cracking of metals are described together with precautions taken in these investigations. Especially designed specimen of low carbon and stainless steels and a titanium alloy and supplementary techniques for obtaining data as to the mechanism of the stress-corrosion process are also described. A specimen and technique recently used to determine whether hydrogen plays a part in the delayed failures of high strength steels in chloride solutions is described.
Key Words: Stress-corrosion; experimental techniques for stress corrosion testing; hydrogen embrittlement; low carbon steels; high strength steels; stainless steels; titanium alloys.

Strain-wave propagation in strips of natural rubber subjected to high-velocity transverse impact, J. C. Smith and C. A. Fenstermaker, J. Appl. Phys. 38, No. 11, 4218-4224 (Oct. 1967). If a flexible filament, marked at intervals along its length is struck transversely by a flying projectile, high speed photography reveals a shifting of the marks caused by passage of a strain wave, and analysis of these shifts provides data on the strain and average strain velocity in the wave. Tests were performed on strips of lightly vulcanized natural rubber at transverse impact velocities up to $65 \mathrm{~m} / \mathrm{s}$, and the resulting strain-velocity distributors analyzed for viscoelastic effects. The analysis showed that although creep effects were small in the observation time interval of $1 \mathrm{msec}$ to $8 \mathrm{msec}$ after impact, significant creep must have occurred at the point of impact within the first millisecond, and additional significant creep occurs at times greater than $8 \mathrm{msec}$. The strain wave front velocity calculated from the quasi-static stress-strain curve was $35.2 \mathrm{~m} / \mathrm{s}$, but a value of approximately $60 \mathrm{~m} / \mathrm{s}$ was observed in the tests. The strain at the wave front, however, tended to attenuate as the wave propagated causing a progressive decrease in the observed value of the strain wave front velocity.

Key Words: Strain waves; natural rubber; viscoelasticity; impact testing; high-speed photography.

Superconducting transition temperatures of semiconducting SrTiO ${ }_{3}$, C. S. Koonce, M. L. Cohen, J. F. Schooley, W. R. Hosler, and E. R. Pfeiffer, Phys. Rev. 163, No. 2, 380-390 (Nov. 10, 1967). The superconducting transition temperature $T_{c}$ of $\mathrm{SrTiO}_{3}$ has been measured for specimens having electron carrier concentrations $n_{c}$ from $6.9 \times 10^{18} \mathrm{~cm}^{-3}$ to $5.5 \times 10^{20} \mathrm{~cm}^{-3}$. The curve exhibits a maximum in $T_{c}$ for $n_{c}$ near $9 \times 10^{19} \mathrm{~cm}^{-3}$. The transition temperature has also been calculated using one adjustable parameter $\xi$, the intervalley deformation potential, in addition to the known normal state properties of $\mathrm{SrTiO}_{3}$. A good fit to the experimental curve is obtained.

Key Words: Semiconductors; $\mathrm{SrTiO}_{3}$; superconductivity; transition temperatures.

The "memory effect" in silver iodide, G. Burley, Act. Cryst. 23, Part 1, 1-5 (July 1967).

Radial distribution and least squares site occupation analyses were performed on powder diffraction patterns of the high temperature phase of silver iodide taken at $155^{\circ} \mathrm{C}$ and $250{ }^{\circ} \mathrm{C}$. A preferential occupation of certain sites by the silver atoms occurs near the transition temperature at $147{ }^{\circ} \mathrm{C}$, involving those silver atom positions nearest to those in the low-temperature wurtzite- and sphalerite-type structures, respectively. The regeneration of a particular derivative low-temperature structure is thus facilitated, and a crystallographic explanation can be given for the observed "memory effect."

Key Words: Crystallography; structure memory; silver iodide; structure; alpha-phase; site-occupation.

Transmission through aluminum of beta-particles emitted by infinitely-thick sources, R. H. Rodriguez-Pasques, P. A. Mullen, G. A. George, and J. E. Harding, Intern. J. Appl. Radiation Isotopes 18, No. 12, 835-847 (1967).

The problem of determining the energy of beta particles emitted from sources containing low concentrations of radioactive substances is examined. Transmission curves of beta particles emitted by "infinitely-thick" disc-shaped sources were obtained with two dif ferent detectors and compared to the curves similarly obtained for beta particles coming from very thin "weightless" deposits on similar solid dises. Different matrix materials and beta-particle energies were used. The curves were studied for shape, secondary radiations and half-thickness. A series of curves were also obtained from four different potassium-salt thick sources, in order to investigate possible influences from variations of effective atomic number. No substantial difference was found between the curves corresponding to the three types of sources, in connection with half-thicknessmaximum-energy relationship.

Guiding rules are proposed for the determination of maximum betaray energies by means of absorption studies and half-thickness determination. 
Key Words: Low-level; beta absorption; beta-particle energy; infinitely-thick sources; half thickness; synthetic beta sources; transmission curves; beta-particle transmission.

\section{Other NBS Publications}

\section{J. Res. NBS 72A (Phys, and Chem), No. 2 (March-April} $1968), \$ 1.00$.

Constant pressure flame calorimetry with fluorine II. The heat of formation of oxygen difluoride. R. C. King and G. T. Armstrong.

The heat of formation of boron carbide. E. S. Domalski and G. T. Armstrong.

Solubility of tris(hydroxymethyl)aminomethane in water-methanol solvent mixtures and medium effects in the dissociation of the protonated base. P. Schindler, R. A. Robinson, and R. G. Bates.

Calibration of the nickel dimethylglyoxime spectral shift at pressures to 20 kilobars for use in spectroscopic pressure measurement. H. W. Davis.

Second virial coefficient of $\mathrm{He}^{4}$ in the temperature range from 2 to $20^{\circ}$ K. M. E. Boyd, S. Y. Larsen, and H. Plumb.

Diffusion rates in organic nuclear materials. A. L. Dragoo.

Effect of oxide additions on the polymorphism of tantalum pentoxide. (system $\mathrm{Ta}_{2} \mathrm{O}_{5}-\mathrm{TiO}_{2}$ ). J. L. W aring and R. S. Roth.

Effect of statistical counting errors on wavelength criteria for $\mathrm{x}$-ray spectra. J. S. Thomsen and F. Y. Yap.

Thermodynamic properties of ammonia as an ideal gas. L. Haar.

\section{J. Res. NBS 72A (Phys. and Chem.), No. 3 (May-June 1968),} $\$ 1.00$.

Jump rates for point defects in special positions held by a trapping center of noncubic symmetry. H. S. Peiser and J. B. Wachtman, Jr.

The thermodynamics of the ternary system: water-potassium chloride-calcium chloride at $25{ }^{\circ} \mathrm{C}$. R. A. Robinson and A. K. Covington.

Force field for $\mathrm{SiF}_{4}$. I. W. Levin and S. Abramowitz.

Blemish formation in processed microfilm. C. I. Pope.

Absolute isotopic abundance ratios of common, equal-atom, and radiogenic lead isotopic standards. E. J. Catanzaro, T. J. Murphy, W. R. Shields, and E. L. Garner.

Role of nickel in Al-10 percent $\mathrm{Si}$ composites containing nickelcoated sapphire whiskers. H. Yakowitz, W. D. Jenkins, and H. Hahn.

\section{J. Res. NBS 72A (Phys. and Chem.), No. 4 (July-August} 1968), \$1.00.

Mass spectrometric study of photoionization. X. Hydrogen chloride and methyl halides. M. Krauss, J. A. Walker, and V. H. Dibeler.

The fourth and fifth spectra of vanadium (V IV and V v). L. Iglesias.

Variation of absorptance-curve shape with changes in pigment concentration. G. L. Howett.

Periodic acid, a novel oxidant of polycyclic aromatic hydrocarbons. A. J. Fatiadi.

A galvanic cell with a low emf-temperature coefficient. G. N. Roberts and W. J. Hamer.

Synthesis of cerite. J. Ito.

Tables of collision integrals for the $(\mathrm{m}, 6)$ potential function for 10 values of $\mathrm{m}$. M. Klein and F. Smith.

Spectrum of relaxation times in $\mathrm{GeO}_{2}$ glass. A. Napolitano and P. B. Macedo.

Resumé of values of the Faraday. W. J. Hamer.

J. Res. NBS $72 B$ (Math. Sci.), No. 2 (April-June 1968), 75 cents.

The probability of an equilibrium point. K. Goldberg, A. J. Goldman, and M. Newman.

Differentiable generalized inverses. J. Z. Hearon and J. W. Evans.

On spaces and maps of generalized inverses. J. Z. Hearon and J. W. Evans.

Principal submatrices V: Some results concerning principal submatrices of arbitrary matrices. R. C. Thompson.

Mathematical basis for the plasma kinetic equations (BBGKY). J. J. Sopka.

On the diffusion of an ion sheet in Poiseuille flow. S. Jarvis, Jr.

A class of thickness-minimal graphs. A. M. Hobbs and J. W. Grossman.
Compendium of $a b$ initio calculations of molecular energies and properties, M. Krauss, Tech. Note 438 (Dec. 1967), 70 cents.

Operations research. Proceedings of a conference for Washington area government agencies, April 20, 1966, Ed. J. A. Joseph, Misc. Publ. 294 (Dec. 1967), 25 cents.

The hyperbolic character of certain experimental results which tend toward limiting values, A. F. Kirstein, Tech. Note 435 (Nov. 1967), 15 cents.

A theorem on arbitrary functions, S. Haber, Am. Math. Monthly 74, No. 8, 973-975 (Oct. 1967).

Algorithms for utilizing Hayward chemical structure notations, S. J. Tauber, G. R. Bolotsky, G. F. Fraction, C. L. Kirby, and G. R. Reed, Proc. ICIREPAT Fifth Annual Meeting, London, England, Aug. 31-Sept. 10, 1965, Chapt. 27, pp. 351-377 (Thompson Book Co., Washington, D.C., 1967).

Analysis of rotationally misaligned stators in the rotary-vane attenuator, W. Larson, IEEE Trans. Instr. Meas. IM-16, No. 3, 225-231 (Sept. 1967).

Born-model calculation of point-defect formation energies in alkalineearth fluorides, A. D. Franklin (Proc. 2nd Meeting Point Defects in Non-metallic Solids, University of Sussex, Brighton, England, Sept. 26-28, 1966), Proc. British Ceramic Soc. 9, 15-24 (July 1967).

Dissociation of $\mathrm{N}_{2}^{+}$and $\mathrm{O}_{2}^{+}$by electron impact, B. Van Zyl and G. H. Dunn, Phys. Rev. 163, No. 1, 43-45 (Nov. 5, 1967).

Effect of chain twisting on the effective barrier to reorientation for a hindered rotator, G. Williams, J. I. Lauritzen, Jr., and J. D. Hoffman, J. Appl. Phys. 38, No. 11, 4203-4208 (Oct. 1967).

Electron affinity of helium via laser photodetachment of its negative ion, B. Brehm, M. A. Gusinow, and J. L. Hall, Phys. Rev. Letters 19, No. 13, 737-741 (Sept. 5, 1967).

Entropy and susceptibility of a pure dipole-dipole substance, J. R. Peverley and P. H. E. Meijer, Phys. Stat. Sol. 23, No. 1, 353-360 (1967).

40 years of precise measurement, W. G. Brombacher, Instr. Control Systems 40, No. 9, 87-92 (Sept. 1967).

Gas-phase photolysis of ethyl iodide at 2537 and $2288 \AA$. Reactions of hot ethyl radicals with added hydrocarbons, R. E. Rebbert and P. Ausloos, J. Chem. Phys, 47, No. 8, 2849-2855 (Oct. 15, 1967).

Inelastic scattering of cold neutrons in polycrystalline gray tin, V. W. Myers, J. Phys. Chem. Solids 28, 2207-2210 (1967).

Inelastic scattering of kilovolt electrons by solids and liquids: determination of energy losses, cross sections, and correlations with optical data, C. J. Powell, Health Phys. 13, No. 12, 1265 (1967).

Mass-spectrometric study of photoionization. VI. $\mathrm{O}_{2}, \mathrm{CO}_{2}, \mathrm{COS}$, and $\mathrm{CS}_{2}$, V. H. Dibeler and J. A. Walker, J. Opt. Soc. Am. 57, No. 8, 1007-1012 (Aug. 1967).

Matrix-isolation study of the reaction of carbon atoms with $\mathrm{HCl}$. The infrared spectrum of the free radical HCCl, M. E. Jacox and D. E. Milligan, J. Chem. Phys. 47, No. 5, 1626-1633 (Sept. 1, 1967).

Neutron-scattering study of hindered rotations in methylbenzenes, J. J. Rush, J. Chem. Phys. 47, No. 10, 3936-3941 (Nov. 15, 1967).

Neutron-scattering study of low-frequency modes in urea and ferroelectric thiourea, J. J. Rush, J. Chem. Phys. 47, No. 10, 42784279 (Nov. 15, 1967).

NMR studies of inorganic fluorides. III. $\mathrm{Si}_{3} \mathrm{~F}_{8}$, R. B. Johannesen, J. Chem. Phys. 47, No. 3, 955-960 (Aug. 1, 1967).

NMR studies of inorganic fluorides. IV. Relative signs of coupling constants in $\mathrm{CH}_{3} \mathrm{SiF}_{3}, \mathrm{HSiF}_{3}$, and $\mathrm{HPF}_{2}, \mathrm{R}$. B. Johannesen, J. Chem. Phys. 47, No. 8, 3088-3089 (Oct. 15, 1967).

$\mathrm{N}_{2} \mathrm{O}$ bond dissociation energy by photon impact, V. H. Dibeler, J. Chem. Phys. 47, No. 6, 2191-2192 (Sept. 15, 1967).

Observing the effect of a change in mass on deBroglie wavelength: the $600-\AA$ bands of ${ }^{3} \mathrm{He}_{2}$, A. L. Smith, J. Chem. Phys. 47, No. 4, 1561-1562 (Aug. 15, 1967).

Pair production by photons on electrons, K. J. Mork, Phys. Rev. 160, No. 5, 1065-1071 (Aug. 1967).

Phenylhydrazono-phenylazo tautomerism. Part II. Structures of 2-oxo-1, 3-bis(phenylhydrazono) compounds and related compounds, A. J. Fatiadi and H. S. Isbell, Carbohydr. Res. 5, 302-319 (1967).

Photolysis of ethylene at 1048-1067 A. Reactions of $\mathrm{C}_{2} \mathrm{H}_{4}+$ and fragmentation of the superexcited ethylene molecule, R. Gorden, Jr. and P. Ausloos, J. Chem. Phys. 47, No. 5, 1799-1806 (Sept. 1, 1967). 
Probability distribution of the radius of gyration of a flexible polymer, S. R. Coriell and J. L. Jackson, J. Math. Phys. 8, No. 6, 1276-1284 (June 1967).

Rotational excitation of diatomic molecules by slow electrons; application to $\mathrm{H}_{2}$, N. F. Lane and S. Geltman, Phys. Rev. 160, No. 1, 53-67 (Aug. 1967).

Stretch scheme, a shell-model description of deformed nuclei, M. Danos and V. Gillet, Phys. Rev. 161, No. 4, 1034-1044 (Sept. 20, 1967).

Structure, isomerization, and cleavage of 1,2-bis(dichloroboryl)ethylene, T. D. Coyle and J. J. Ritter, J. Am. Chem. Soc. 89, 5739-5740 (1967).

Superposition of configurations and atomic oscillator strengthscarbon I and II, A. W. Weiss, Phys. Rev. 162, No. 1, 71-80 (Oct. 5, 1967).

SU(3), meson-baryon scattering, and asymptotic limits, S. Meshkov and G. B. Yodh, Phys. Rev. Letters 19, No. 10, 603-608 (Sept. 4, 1967).
Twin configurations in FCC dendrites, J. W. Faust, Jr., F. Ogburn, D. Kahan, and A. W. Ruff, Jr., J. Electrochem. Soc.: Solid State Science 114, No. 12, 1211-1212 (Dec. 1967).

User reaction as a system design tool at CFSTI, P. F. Urbach, Proc. Fourth Annual National Colloquium on Information Retrieval, May 3-4, 1967, Ed. A. B. Tonik, pp. 7-18 (International Information, Inc., Philadelphia, Pa., 1967).

*Publications for which a price is indicated are available by purchase from the Superintendent of Documents, U.S. Government Printing Office, Washington, D.C. 20402 (foreign postage, one-fourth additional). The NBS non-periodical series are also available from the Clearinghouse for Federal Scientific and Technical Information, Springfield, Va. 22151. Reprints from outside journals and the NBS Journal of Research may often be obtained directly from the authors. 